\title{
La reconfiguración del derecho humano a migrar: tensiones entre los principios de igualdad y no discriminación en Argentina y Ecuador* / The reconfiguration
} of the human right to migrate: tensions between the principles of equality and non-discrimination in Argentina and Ecuador

\author{
Verónica Jaramillo Fonnegra** \\ Silvana Estefanía Santi Pereyra***
}

\begin{abstract}
RESUMEN
A comienzos del nuevo milenio, la ratificación de las normas de derechos humanos en los paises latinoamericanos, asi como la lenta incorporación de esos estándares internacionales a la legislación local, fueron el telón de fondo para reconocer el derecho a migrar como un derecho humano en la ley migratoria de Argentina (2004) y la Carta Magna de Ecuador (2008). En este artículo, exponemos cómo el derecho humano a migrar ha sido reconfigurado en Argentina y Ecuador, según distintos momentos políticos y cambios en los flujos migratorios. Adoptamos el método del estudio de caso, desde una mirada comparada, para observar que, en la evolución de los últimos veinte años, se han presentado algunas disposiciones, leyes y prácticas adoptadas en estos dos países que interpelan los principios de igualdad y no discriminación en el cumplimiento efectivo de los derechos.
\end{abstract}

PALABRAS CLAVE: Derechos humanos, regularización, control migratorio, Argentina, Ecuador.

\begin{abstract}
At the beginning of the new millennium, the ratification of the norms pertaining to human rights in Latin American countries and the slow incorporation of these international standards into local legislation provided the backdrop for the recognition of the right to migrate as a human right in Argentina's Migration Law (2004) and the Magna Carta of Ecuador (2008). The present article sets out how the human right to migrate has been reconfigured in Argentina and Ecuador, in light of distinct political moments and changes in migratory flow. We adopt the case study method, from a comparative perspective, observing that, over the course of the last twenty years, these two countries have adopted various provisions, laws, and practices that question the principles of equality and non-discrimination in the effective enforcement of rights.
\end{abstract}

KEY WORDS: Human rights, regularization, migration control, Argentina, Ecuador.

\footnotetext{
* Artículo de investigación. Recibido el 28 de enero de 2020 y aceptado para su publicación el 16 de julio de 2020.

** Profesora investigadora en la Universidad Nacional de Lanús, Argentina. / verojarafonn@gmail.com / orcid. org/0000-0003-1116-3780

***Doctoranda en la Universidad de Belgrano, Argentina./ silvanasanti@hotmail.com/ orcid.org/0000-0002-7388-4631
} 


\section{SUMARIO}

1. Introducción

2. La excepcionalidad de los derechos de las personas migrantes

3. Los casos de Argentina y Ecuador

4. La excepcionalidad como regla

5. La regularización en épocas de derechos humanos

6. A modo de cierre: ¿Politicas migratorias de derechos humanos selectivas?

"Toda reflexión y toda política racional sobre inmigración debería partir del reconocimiento de que se trata de un hecho irreversible, que es el resultado de la inicua estructura económica del planeta: el fenómeno migratorio no es una emergencia, sino un hecho estructural e imparable, que ya implica a cientos de millones de personas, que crece constantemente y que está destinado a desarrollarse indefinidamente".

Luigi Ferrajoli, 2019*

\section{Introducción}

En este artículo comprenderemos a los derechos humanos como construcciones históricas derivadas de sistemas supranacionales que expresan consensos globales sobre garantías y protecciones. El avance de cada uno de los derechos humanos, en clave internacional y local, puede leerse como producto de grandes acuerdos que también están permeados por los sistemas de dominación a nivel planetario. ${ }^{1} \mathrm{Si}$ bien algunos autores reconocen que los derechos humanos son parte del fenómeno de la globalización y de la neoliberalización de las sociedades occidentales, otros consideran que han surgido frente a un nuevo marco de reivindicaciones para los sectores vulnerados, que encuentran en ellos un verdadero mecanismo emancipador. ${ }^{2}$

Formalmente, los derechos humanos conforman un marco normativo a nivel internacional, fundamental para la defensa de todas las personas, sin importar cuál sea su condición. De hecho, la noción de derechos humanos tiene que ver con la dignidad de la persona frente al Estado, pues se entiende que:

\footnotetext{
* Ferrajoli, Luigi, "Políticas contra los migrantes y crisis de la civilidad jurídica", Revista Crítica Penal y Poder, núm. 18.

1 "Entre leyes y experiencias. El acceso a la justicia de las trabajadoras domésticas migrantes a comienzos del siglo xxı en la Ciudad Autónoma de Buenos Aires", tesis de doctorado en Ciencias Sociales, Facultad de Ciencias Sociales, Universidad de Buenos Aires, 2017.

2 SASSEN, SASKIA, Contrageografías de la globalización. Género y ciudadanía en los circuitos transfronterizos, Madrid, Traficantes de Sueños, 2003. RAJAGopaL, BALAKRISHNAN, "Los límites del derecho en la globalización contrahegemónica: la Corte Suprema de la India y la lucha en el valle de Narmada", en Santos, Boaventura de Sousa y Rodríguez Garavito, César (eds.), El derecho y la globalización desde abajo: Hacia una legalidad cosmopolita, BarcelonaMéxico, Anthropos-Uam, 2007, pp. 167-196.
} 
El poder público debe ejercerse al servicio del ser humano: no puede ser empleado lícitamente para ofender atributos inherentes a la persona y debe ser vehículo para que ella pueda vivir en sociedad en condiciones cónsonas con la misma dignidad que le es consustancial. La sociedad contemporánea reconoce que todo ser humano, por el hecho de serlo, tiene derechos frente al Estado, derechos que éste o bien tiene el deber de respetar y garantizar o bien está llamado a organizar su acción a fin de satisfacer su plena realización. Estos derechos, atributos de toda persona e inherentes a su dignidad, que el Estado está en el deber de respetar, garantizar o satisfacer son los que hoy conocemos como derechos humanos. ${ }^{3}$

Este concepto es reconocido y avalado por la mayoría de las democracias occidentales, quienes ceden parte de sus soberanías para que organismos internacionales evalúen la situación de derechos humanos en sus países, a través de informes periódicos o por medio de denuncias individuales. Pero, además, los derechos humanos están en constante reconfiguración: desde su creación formal se han reinventado varias veces en distintos instrumentos que amplían o complejizan el acceso de ciertos derechos.

Por otro lado, podemos considerar que en la actualidad los derechos humanos se presentan como construcciones legales propias del sistema capitalista, colonialista ${ }^{4}$ patriarcal. ${ }^{5}$ Así, las normas son dictadas por las élites que actúan a través de instituciones donde se expresa el derecho, las cuales "fueron delineadas de acuerdo a los intereses de quienes tuvieron el poder para crearlas". ${ }^{6}$

Es por lo anterior que algunos autores consideran que:

La concepción hegemónica y nortecéntrica de los derechos humanos se encuentra en una encrucijada en cuanto al lenguaje emancipador de transformación de las sociedades. La estrechez y la selectividad de sus propósitos se muestran incapaces de confrontar las sistemáticas

\footnotetext{
${ }^{3}$ Nikken, Pedro, "El concepto de derechos humanos", en Estudios básicos de derechos humanos, San José, IDHH, 1994, p. 15.

${ }^{4}$ Spivak, Gayatri Chakravorty, A Critique of Postcolonial Reason: Toward a History of the Vanishing Present, Cambridge, Harvard University Press, 1999. BнавнA, Hoмl, Nuevas minorías, nuevos derechos: Notas sobre cosmopolitismos vernáculos, Buenos Aires, Siglo XXI, 2013. Grosfoguel, Ramón, El giro decolonial, reflexiones para una diversidad epistémica más allá del capitalismo global, Bogotá, Encuentros, 2007.

${ }^{5}$ FEDERICI, SILVIA, La revolución feminista inacabada. Mujeres, reproducción social y lucha por lo común, México, Escuela Calpulli, 2013.

${ }^{6}$ Robles, DiEgo, "El acceso a la justicia: aspectos teóricos, implicancias prácticas", en Manuela González y Carlos Lista (coords.), Sociología jurídica en Argentina: tendencias y perspectivas, Buenos Aires, Eudeba, 2011, p. 63.
} 
injusticias y opresiones causadas por el capitalismo, el colonialismo y el patriarcado"?.

En este artículo, nos proponemos evidenciar cómo funciona esa estrechez y selectividad de los derechos humanos en dos países: Argentina y Ecuador. La idea es exponer cómo los derechos de las personas migrantes se han reconfigurado según distintos momentos políticos y cambios en los flujos migratorios. Si bien ambos países han establecido el derecho a migrar como derecho humano, el acceso a este derecho se ha visto limitado o condicionado por decisiones ancladas en vaivenes políticos. De tal modo, se recodifican a partir de normas y prácticas que ponen en tensión la igualdad y no discriminación. Cabe puntualizar que estos son principios imprescindibles para la génesis de la idea de derechos humanos; sin ellos, enunciar la migración como derecho humano desdibuja su sentido.

Nuestra propuesta es analizar de qué manera las intenciones de reconocimiento de derechos fueron parciales o se hicieron como medidas excepcionales, más bien, sustentadas en una forma de inclusión-exclusión. ${ }^{8}$ Esto puede evidenciarse en las nuevas categorías migratorias creadas por la ley, las cuales otorgan más derechos, pero todavía hay grupos que se encuentran excluidos de la igualdad plena. Lo que caracteriza a la excepción es que el objeto de exclusión no está simplemente desligado de la ley; al contrario, la ley se mantiene en relación con él bajo la forma de la suspensión. La norma se aplica, entonces a la excepción, desaplicándose, retirándose de ella. "La excepción es realmente, según una etimología posible del término (ex-capere), cogida desde fuera, incluida a través de su misma exclusión". ${ }^{9}$

Para demostrar nuestra premisa, recurriremos a una metodología de corte cualitativo, adoptando el método del estudio de caso ${ }^{10}$ como "una estrategia de investigación comprensiva", ${ }^{11}$ desde una mirada comparada. Nos situaremos en el campo de las políticas migratorias, atendiendo a los cambios acaecidos en Argentina y Ecuador en materia de migración y derechos humanos en los últimos veinte años.

\footnotetext{
7 Boaventura de Sousa, Santos y Sena Martins, Bruno, "Introducción", en Santos, Boaventura de Sousa y Sena Martins, Bruno (eds.) El pluriverso de los derechos humanos. La diversidad de las luchas por la dignidad, Buenos Aires, Akal, 2019, p. 7.

${ }^{8}$ Agamben, Giorgio, La comunidad que viene, Valencia, Pre-textos, 1996.

${ }_{9}^{9}$ Agamben, Giorgio, La comunidad que viene, Valencia, Pre-textos, 1996, p. 1.

${ }^{10} \mathrm{El}$ caso se define "como un sistema delimitado en tiempo y espacio de actores, relaciones e instituciones sociales donde se busca dar cuenta de la particularidad del mismo en el marco de su complejidad". Neiman, Guillermo y QuARANTA, Germán, "Los estudios de caso en la investigación sociológica", en Gialdino Vasilachis (comp.), Estrategias de investigación cualitativa, Buenos Aires, Gedisa, 2006, p. 220.

${ }^{11}$ YIN, RoBerT, Case study research: Design and methods, California, Sage, 1994, p. 13.
} 
La selección de casos se respalda en que ambos fueron los primeros países sudamericanos en reconocer el derecho a migrar como derecho humano, ${ }^{12} \mathrm{a}$ través de instrumentos jurídicos de distinto rango: Argentina lo hizo en la ley migratoria de 2004 y Ecuador en su Carta Magna de 2008. Este encuadre normativo diferenciado es un elemento que favorece la comparación, así como la distancia temporal; desde su sanción, se puede examinar la aplicación o exceptuación del derecho a migrar en ambos contextos.

Otra diferencia que podemos identificar entre ambos corpus normativos es que el derecho a migrar consagrado en la ley migratoria argentina era restrictivo desde su inicio, dado que estaba atado a un proyecto de integración regional dirigido a los mercosureños. La concepción de derechos humanos aplicada a las migraciones en la Constitución ecuatoriana se encontraba en otra línea, pues era más amplia e implicaba la construcción de una ciudadanía universal que no distinguía entre nacionalidades.

Para este análisis, nos valdremos de documentos de carácter oficial, tales como leyes, decretos, actos administrativos y otras normativas; además de presentaciones internacionales de ambos países ante Naciones Unidas, informes país e informes alternativos o informes sombra, presentados por las organizaciones de derechos humanos y defensa de las personas migrantes. Consideramos que el análisis documental brinda la posibilidad de evaluar formas específicas y organizadas de pensar y son una forma de analizar históricamente las transformaciones del pensamiento y de los conocimientos. ${ }^{13}$ Además, cuando los documentos contienen normas esgrimidas por el Estado, los podemos considerar como una radiografía histórica de dicho Estado y del momento económico y social de un país. ${ }^{14}$

\section{La excepcionalidad de los derechos de las personas migrantes}

Uno de los temas más frágiles al hablar de derechos humanos es quizás el que se refiere a personas migrantes. De hecho, pocos países han acompañado procesos legales en las temáticas referentes a los derechos de la población migrante. En la actualidad contamos con consagraciones tímidas y sus instrumentos han tenido escasa ratificación. Inclusive, en el ámbito del sistema

\footnotetext{
${ }^{12}$ Luego, varios Estados adoptaron la perspectiva de derechos humanos para encarar las migraciones, dando lugar a un "giro humanístico" o "humanización" de las legislaciones y políticas migratorias en la región. GARCiA, LILA, "Migraciones, Estado y una política del derecho humano a migrar: ¿hacia una nueva era en América Latina?", Colombia Internacional, núm. 88, p. 109.

${ }^{13}$ Foucault, Michel, Vigilar y castigar: nacimiento de la prisión, Buenos Aires, Siglo XXI, 2003.

${ }^{14}$ Novick, Susana, Cómo trabajar con textos jurídicos en ciencias sociales, documento de trabajo núm. 69, Buenos Aires, Instituto de Investigaciones Gino Germani, Facultad de Ciencias Sociales, Universidad de Buenos Aires, 2014.
} 
interamericano, ni siquiera existe un tratado internacional que específicamente obligue a los Estados a cumplir derechos para este tipo de población. Por su parte, la Convención Internacional para todos los Trabajadores Migratorios y sus Familiares (cмw, por sus siglas en inglés) es una de las normas internacionales menos ratificadas a nivel mundial.

Y ello no se debe a que la migración sea un tema sin visibilidad o que se ausente de la agenda para muchos Estados. De hecho, recientemente las Naciones Unidas propiciaron nuevos acuerdos internacionales para el tratamiento internacional de la migración. Junto con la Declaración de Nueva York (2016) y los Pactos Globales sobre Migración y Refugio (2018), se han venido estableciendo nuevos marcos legales que fueron concebidos al margen de los mecanismos coercitivos de derechos humanos. Sin embargo, estos no son vinculantes y no cuentan con competencia contenciosa, por lo cual su contenido queda como una mera declaración de intenciones. Además, al analizar estos instrumentos, tampoco encontramos ideas superadoras para los derechos de las personas migrantes, porque se enmarcan en la idea de establecer una migración "segura, ordenada y regular", en la que priman criterios de selectividad.

Pese a lo inocuo de las normas internacionales sobre migrantes para la soberanía de los Estados, y a la poca ratificación de las existentes, Argentina y Ecuador hacen parte de diversos instrumentos internacionales de derechos humanos que los obligan a reconocerlos sin importar condición alguna. En ellos, la igualdad y no discriminación son regla y esto puede encontrarse inclusive en la cMw y en los pactos globales sobre migración y refugio.

La igualdad y la no discriminación han sido uno de los pilares en el desarrollo de los derechos humanos. Justamente, la Declaración Universal de Derechos Humanos (1948) establece una cláusula de igualdad que reza: “Todos los seres humanos nacen libres e iguales en dignidad y derechos y, dotados como están de razón y conciencia, deben comportarse fraternalmente los unos con los otros". ${ }^{15}$ Esta premisa de carácter universal pretendió prevenir que se repitieran los horrores vividos en la Segunda Guerra Mundial y, con ello, dotar de la misma dignidad y derechos a todas las personas del mundo. Conscientes de las diferencias que se trazan a nivel global entre las distintas sociedades, quienes redactaron esta declaración decidieron además avanzar en una cláusula de no discriminación:

Toda persona tiene todos los derechos y libertades proclamados en esta Declaración, sin distinción alguna de raza, color, sexo, idioma, religión,

\footnotetext{
${ }^{15}$ Declaración Universal de Derechos Humanos, Paris, 10 de diciembre de 1948, art. 1.
} 
opinión política o de cualquier otra índole, origen nacional o social, posición económica, nacimiento o cualquier otra condición. Además, no se hará distinción alguna fundada en la condición política, jurídica o internacional del país o territorio de cuya jurisdicción dependa una persona, tanto si se trata de un país independiente, como de un territorio bajo administración fiduciaria, no autónomo o sometido a cualquier otra limitación de soberanía. ${ }^{16}$

Estos dos principios, el de igualdad y el de no discriminación, también se repiten en diversos tratados, pactos, constituciones y normas, tanto nacionales como internacionales. También son una base central del sistema de derechos humanos, donde se enlistan el Pacto Internacional de Derechos Civiles y Políticos (1966) (artículo 26); el Pacto Internacional de Derechos Económicos, Sociales y Culturales (1966) (artículo 2.2); la Convención sobre la Eliminación de Todas las Formas de Discriminación contra la Mujer (1979); la Convención Internacional sobre la Protección de los Derechos de Todos los Trabajadores Migratorios y de sus Familiares (1990) (artículo 1), entre otros.

En el Sistema Interamericano de Derechos Humanos, la igualdad y la no discriminación se mencionan en la Convención Americana de Derechos Humanos (1969) (artículo 24); el Protocolo de San Salvador (1988) (artículo 3); la Convención Interamericana para Prevenir, Sancionar y Erradicar la Violencia contra la Mujer-Convención de Belém do Pará (1994) (artículo 9), por citar algunos ejemplos.

Diversos desarrollos doctrinarios y jurisprudenciales se han dado, tanto en el sistema universal como en el interamericano, para referirse al principio de igualdad y no discriminación. Ello se debe a que esta es una norma de jus cogens en el derecho internacional de los derechos humanos. Así lo ha expresado, en 2003, la Corte Interamericana en su Opinión Consultiva 18/03:

El principio de igualdad ante la ley, igual protección ante la ley y no discriminación, pertenece al jus cogens, puesto que sobre él descansa todo el andamiaje jurídico del orden público nacional e internacional y es un principio fundamental que permea todo ordenamiento jurídico. Hoy día no se admite ningún acto jurídico que entre en conflicto con dicho principio fundamental, no se admiten tratos discriminatorios en perjuicio de ninguna persona, por motivos de género, raza, color, idioma, religión o convicción, opinión política o de otra índole, origen

\footnotetext{
${ }^{16}$ Declaración Universal de Derechos Humanos, Paris, 10 de diciembre de 1948, art. 2.
} 
nacional, étnico o social, nacionalidad, edad, situación económica, patrimonio, estado civil, nacimiento o cualquier otra condición. En la actual etapa de la evolución del derecho internacional, el principio fundamental de igualdad y no discriminación ha ingresado en el dominio del jus cogens. Por lo anterior, cualquier actuación que se realice sobre la población migrante tendría cuanto menos la obligación de incluir las cláusulas de igualdad y no discriminación en el análisis de todo tipo de situación. ${ }^{17}$

Ahora bien, es preciso aclarar que no toda distinción se considera discriminatoria. En algunos casos, la distinción obedece a un fin legítimo o a una "discriminación positiva" $y$, si la medida que se aplica es proporcional, no puede hablarse de discriminación. Pero, para establecer esta proporcionalidad, es importante comprender que, dentro del sistema interamericano, por ejemplo, la nacionalidad es uno de los criterios prohibidos previsto en el artículo 1 de la Convención Americana. Así, indica que, si el Estado hace una distinción basada en un origen nacional, debe explicar cuál es el fin legítimo de la medida y que este se fundamente en una necesidad social imperiosa que lo justifique. Es decir, el Estado debe demostrar la proporcionalidad, utilizando las medidas menos restrictivas para lograr el mismo fin. ${ }^{18}$

Saldada la cuestión central sobre la igualdad y no discriminación como principios de los derechos humanos que deben aplicársele a la población migrante, es preciso preguntarnos, entonces: ¿existe un derecho humano a migrar? La respuesta corta es no, no existe ninguna consagración legal en los tratados de derechos humanos que establezca expresamente el derecho humano a migrar. ${ }^{19}$ Pero en distintos tratados internacionales existe una cláusula que establece la libre circulación. ${ }^{20}$

${ }^{17}$ Corte Interamericana de Derechos Humanos, Condición Juridica y Derechos de los Migrantes Indocumentados, Opinión Consultiva OC-18/03 de 17 de septiembre de 2003, párrafo 101.

${ }^{18}$ Comisión Interamericana de Derechos Humanos, "Derechos humanos de migrantes, refugiados, apátridas, víctimas de trata de personas y desplazados internos: Normas y estándares del Sistema Interamericano de Derechos Humanos", 2015. Disponible en: https://www.oas.org/es/cidh/informes/pdfs/MovilidadHumana.pdf

${ }^{19}$ GARCiA, LILA, "Migraciones, Estado y una política del derecho humano a migrar: ¿hacia una nueva era en América Latina?", Colombia Internacional, núm. 88, pp. 107-133.

${ }^{20}$ Por ejemplo, la Declaración Universal de Derechos Humanos, en su artículo 13, establece: "1. Toda persona tiene derecho a circular libremente y a elegir su residencia en el territorio de un Estado. 2. Toda persona tiene derecho a salir de cualquier país, incluso del propio, y a regresar a su país". Asimismo, la Convención Americana de Derechos Humanos, en su artículo 22, considera que hay un derecho de circulación y de residencia y consagra que: "1. Toda persona que se halle legalmente en el territorio de un Estado tiene derecho a circular por el mismo y a residir en él con sujeción a las disposiciones legales. 2. Toda persona tiene derecho a salir libremente de cualquier país, inclusive del propio". 
Podemos decir entonces que el derecho a migrar se ha configurado a través del derecho a la libre circulación, es decir, desde el derecho a salir de cualquier país, incluso del propio, pues no es factible concebir la posibilidad de salir de un territorio sin entrar a otro, o permanecer en un limbo estatal. Por otra parte, en el caso de Argentina y Ecuador, el derecho humano a migrar se ha incorporado como un derecho humano autónomo, al invocar el principio pro homine o pro personae. Es decir, el principio de la aplicación de la norma más beneficiosa para la persona. Así, el derecho a migrar se encuentra en ambas legislaciones: como "esencial e inalienable", en el caso argentino, y como el derecho a "la libre movilidad de todos los habitantes del planeta", en el caso ecuatoriano.

La ley migratoria argentina, a juicio de Ceriani, se pronuncia de manera clara y favorable acerca de la discusión jurídica sobre si la migración es un derecho o no, pues lo reconoce. ${ }^{21}$ Mientras, para Hinés, el reconocimiento del derecho fundamental a migrar es la disposición más novedosa de la norma migratoria argentina. Sobre este punto, la autora aclara que "si bien la ley no prevé fronteras abiertas, no deja de reflejar una orientación filosófica y de derechos humanos". ${ }^{22}$ Por su parte, la inclusión del derecho a migrar en la Constitución ecuatoriana implica un hito jurídico que habilita "un tratamiento especial a la migración, a partir de una nueva reflexión desde la ciudadanía, donde las personas migrantes y sus familias puedan ejercer sus derechos". ${ }^{23}$

Si bien, tanto Argentina como Ecuador se paran frente a la cuestión migratoria desde una perspectiva de derechos humanos, podemos identificar que ambos países incluyen a su vez en su legislación diferentes situaciones que relativizan el derecho a migrar. En esta línea, a lo largo de los años, se han presentado algunas disposiciones, leyes y prácticas adoptadas en estos dos países que interpelan los principios de igualdad y no discriminación a los que hemos hecho referencia, y que se tornan en material para nuestro análisis.

Sostenemos que omitir los principios de igualdad y no discriminación -base de los derechos humanos-, a través de medidas políticas parcializadas y excepcionales para ciertas nacionalidades provoca una fragmentación de la figura del migrante como sujeto de derechos. Ello produce un debilitamiento de la idea de derechos humanos, al condicionar ciertos derechos a los momentos políticos y nacionalidades de las que se trate.

\footnotetext{
${ }^{21}$ Ceriani Cernadas, Pablo, "Nueva Ley: un paso hacia una concepción distinta de la migración", en Rubén Giustiniani (ed.), Migración: un derecho humano, Buenos Aires, Prometeo, 2004.

${ }^{22}$ HinÉS, BÁRBARA, "El derecho a migrar como un derecho humano: La actual ley inmigratoria argentina", Revista Derecho Público (Argentina), año 1, núm. 2, p. 323-324.

${ }^{23}$ Quiloango Tipanluisa, Susana, "Políticas públicas migratorias en el Ecuador", Documentos de Trabajo, Quito, Fundación Friedrich Ebert, 2011, p. 9.
} 
Lo anterior propicia que el sujeto de derechos construido políticamente en Argentina y Ecuador sea desigual, de acuerdo con las prácticas estatales y los distintos momentos históricos. Dar mayores facilidades o dificultades para el ingreso o permanencia a diferentes grupos migrantes repercute en su acceso a derechos y cristaliza una construcción desigual de los sujetos migrantes que conviven en un mismo territorio. En ambos países estamos ante una hipotética igualdad de derechos para los migrantes que, atravesada por las disposiciones y políticas excepcionales, genera desigualdades de hecho.

\section{Los casos de Argentina y Ecuador}

A comienzos del nuevo milenio, la ratificación de las normas de derechos humanos en los países latinoamericanos y la incorporación lenta de esos estándares internacionales a la legislación local coincidieron con un contexto de emigración, mayoritariamente, de sus poblaciones hacia países del norte global. Paralelamente, en esos años, la región consolidó importantes avances y reconocimientos para la población migrante, pero sin dejar de lado las perspectivas de control migratorio. Esto se refleja en las aprobaciones o debates de nuevas normativas migratorias en varios Estados sudamericanos que han tenido en su eje una óptica de derechos humanos.

Una de las primeras medidas que se adoptó en la región para pensar la migración como derecho humano tuvo que ver con la firma entre Argentina, Brasil, Paraguay y Uruguay del Acuerdo sobre Residencia para Nacionales de los Estados Parte del Mercosur y Asociados, en 2002. Allí, se crearon normas comunes para la regularización migratoria de las personas provenientes de los países firmantes. Posteriormente, se sumaron a estos acuerdos Bolivia, Chile, Colombia, Ecuador y Perú, Venezuela, Guyana y Surinam.

El paradigma que pretendía dejar atrás a países como Argentina era el que se había instaurado en la última dictadura militar y que expidió en 1981 la denominada Ley General de Migraciones y Fomento de la Inmigración 22.439, conocida como "ley Videla", cuya vigencia permaneció hasta $2004 .{ }^{24}$ Bajo esta norma, los procedimientos de regularización eran complejos, se exigían visas y contratos laborales que condicionaban la permanencia en el país. Muchas personas solo accedian a la documentación por medio de amnistías que frecuentemente eran otorgadas según la nacionalidad.

\footnotetext{
${ }^{24}$ COURTIS, CoRINA, "Hacia la derogación de la Ley Videla: la migración como tema de labor parlamentaria en la Argentina de la década de 1990", en Alejandro Grimson y Elizabeth Jelin (comps.), Migraciones regionales hacia la Argentina. Diferencia, desigualdad y derechos, Buenos Aires, Prometeo, 2006, pp. 162-205.
} 
Para el año 2003, Argentina sancionó la Ley 25.871 de Migraciones, la cual fue pionera a nivel sudamericano, pues, en su artículo 4, estableció la migración como un derecho humano. Esta ley señaló que la regularización migratoria es un derecho del migrante y una obligación del Estado. ${ }^{25}$ Años después, en 2010, se dictó su reglamentación por medio del Decreto 616/10 que hizo más ágiles algunas medidas para la regularización y dotó de contenido a algunos artículos. En 2017, la Ley 25.871 sufrió una modificación por medio del Decreto de Necesidad y Urgencia 70/17.

Siguiendo esta impronta, Ecuador en su Constitución de 2008 reconoció el derecho a migrar y estableció el respeto de los derechos humanos de las personas migrantes como principio de sus relaciones internacionales. Esto marcó una distancia respecto de la visión de seguridad nacional plasmada en la ley de migración de 1971, imperante en ese momento. Durante mucho tiempo, ese país andino mantuvo esos principios solo en la Constitución nacional, pero sin concretar una nueva ley migratoria acorde. Ello ocasionó un proceso de doble estándar -acorde con el rango normativo diferenciado-. Así, en los discursos y las prácticas estatales, la migración se consideraba un derecho humano, especialmente cuando se hablaba de la emigración ecuatoriana. Pero, al momento de actuar sobre la inmigración en territorio nacional, se apelaba más a cuestiones de seguridad y control.

Luego de años de debates políticos, recién en 2017, el país andino aprobó la Ley Orgánica de Movilidad Humana, siguiendo la Carta Magna ecuatoriana. Ese texto jurídico también se posiciona desde una visión de derechos humanos en varios de sus considerandos y artículos. Sin embargo, desde 2019, Ecuador tiene en carpeta un nuevo proyecto para modificar la ley de movilidad humana. Este endurece la normativa vigente, aunque conserva la perspectiva de derechos humanos en línea con la Constitución. Una muestra de ello fue que, en junio de 2020, el foco del primer debate en la Asamblea Nacional de Ecuador estuvo centrado en aumentar las causales para la inadmisión y la deportación de extranjeros, en un país de prominente emigración y tránsito.

Por su parte, Argentina tiene una gran tradición migratoria, desde los origenes del Estado-nación ha recibido a gente de distintas nacionalidades. De hecho, el país austral ha sido uno de los principales destinos de la región sudamericana, tanto para migrantes regionales como extracontinentales. Para 2019, en Argentina había 2212879 de personas migrantes, lo cual equivale a 4.9\% de la

\footnotetext{
${ }^{25}$ Novick, SusanA, "Migración y políticas en Argentina: Tres leyes para un país extenso (1876-2004)", en Susana Novick (comp.), Las migraciones en América Latina: políticas, culturas y estrategias, Buenos Aires, Catálogos-Clacso, 2008, pp. 131-152.
} 
población total del país. ${ }^{26}$ En la actualidad, 81.5\% de la población migrante en Argentina proviene de la región americana, $16.6 \%$ es europea y $1.7 \%$ asiática. ${ }^{27}$ Principalmente, hay bolivianos, paraguayos, venezolanos, peruanos y chilenos. ${ }^{28}$

Por su parte, Ecuador históricamente ha recibido inmigración transfronteriza peruana y colombiana y, desde 2008, ha visto llegar nuevas corrientes migratorias desde Cuba, Haití, distintos países africanos y asiáticos, además de otros países del norte, hasta llegar a la reciente migración venezolana. ${ }^{29}$ Los datos oficiales señalan que, hasta mediados de 2019, se contabilizaban 381500 migrantes internacionales, es decir, 2.2\% sobre el total de la población de Ecuador..$^{30}$ Como precedente del incremento escalonado de los venezolanos, los flujos migratorios más numerosos en Ecuador han sido los provenientes de Colombia, Cuba, Perú y Haití. ${ }^{31}$

Sin lugar a duda, el cambio más reciente y significativo en las tendencias migratorias en la región es el desplazamiento desde Venezuela, que ha venido creciendo en los últimos años. ${ }^{32}$ Desde 2016, se han reportado $4769498^{33}$ venezolanos fuera de su país, cuya mayoría habita y transita por el continente americano. ${ }^{34}$ En Argentina, hasta enero de 2019, había unos 180 267, y 2675 solicitudes de asilo. ${ }^{35}$ Hasta agosto de 2019, Ecuador ha recibido 385042

\footnotetext{
${ }^{26}$ Organización Internacional para las Migraciones, Portal de Datos Mundiales sobre la Migración. Disponible en: https:// migrationdataportal.org/es?i=stock_abs_\&t $=2019 \& \mathrm{tcm} 49=218$

${ }^{27}$ Organización Internacional para las Migraciones y Consejo Nacional de Coordinación de Politicas Sociales, "Escenario base para el seguimiento de los objetivos de desarrollo sostenible vinculados a las condiciones de vida de los migrantes a través del gasto público social nacional", 2018. Disponible en: http://argentina.iom.int/co/sites/default/files/publicaciones/ Escenario\%20base\%200DS\%20Condiciones\%20de\%20Vida\%20Migrantes\%20\%20WEB\%20FINAL.pdf

${ }^{28}$ Universidad Nacional de Lanús, "¿Regresividad en Derechos Humanos? El Decreto de Necesidad y Urgencia 70/17 y su impacto en el acceso a la justicia de las personas migrantes frente a los procedimientos de expulsión y detención", pedido de informes realizado en el marco del Proyecto Oscar avsik, 2018.

${ }^{29}$ Herrera, Gioconda y Cabezas Gálvez, Gabriela, "Ecuador: de la recepción a la disuasión. Políticas frente a la población venezolana y experiencia migratoria 2015-2018", en Luciana Gandini, Fernando Lozano Ascencio y Victoria Prieto (coords.), Crisis y migración de la población venezolana. Entre la desprotección y la seguridad jurídica en Latinoamérica, México, UNAM, 2019, pp. 125-155.

${ }^{30}$ Organización Internacional para las Migraciones, Portal de Datos Mundiales sobre la Migración. Disponible en: https:// migrationdataportal.org/es?i=stock_abs_\&t $=2019 \& \mathrm{tcm} 49=218$

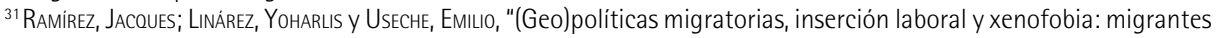
venezolanos en Ecuador", en Cécile Blouin (ed.), Después de la llegada. Realidades de la migración venezolana, Lima, Themis-PucP, 2019, pp. 1-29.

${ }^{32}$ Organización Internacional para las Migraciones y Consejo Nacional de Coordinación de Politicas Sociales, "Escenario base para el seguimiento de los objetivos de desarrollo sostenible vinculados a las condiciones de vida de los migrantes a través del gasto público social nacional", 2018. Disponible en: http://argentina.iom.int/co/sites/default/files/publicaciones/ Escenario\%20base\%200DS\%20Condiciones\%20de\%20Vida\%20Migrantes\%20\%20WEB\%20FINAL.pdf

${ }^{33}$ Cifra actualizada al 5 de diciembre de 2019.

${ }^{34}{ }_{R} 4 \mathrm{~V}$, "Plataforma de coordinación para refugiados y migrantes de Venezuela". Disponible en: https://r4v.info/es/ situations/platform

${ }^{35}{ }_{\mathrm{R}} 4 \mathrm{~V}$, "Plataforma de coordinación para refugiados y migrantes de Venezuela". Disponible en: https://r4v.info/es/ situations/platform
} 
migrantes y refugiados provenientes de Venezuela, de los cuales se sumaban 13535 solicitantes de asilo. ${ }^{36}$

En ambos países este flujo nuevo y continuado, en pocos años, ha pasado a ser muy significativo y evaluado como una situación de crisis o emergencia sobre la que hay que generar acciones concretas y mancomunadas entre los distintos actores políticos y sociales. Pero la idea de crisis o emergencia facilita la creación de medidas de excepción que no siempre cumplen con los principios de igualdad y no discriminación. Al trazar un horizonte desigual, donde, de acuerdo con el origen nacional, se accede a ciertos beneficios o se encuentran mayores barreras, se construye un panorama discrecional que algunas veces se disfraza de discriminación positiva.

Por ejemplo, en Argentina, a razón del "aumento de migrantes venezolanos”, se establecieron algunas medidas para favorecer a esta población y, al mismo tiempo, se creó un nuevo sistema de radicación a distancia que se aplicó a todas las personas migrantes. Esto retrasó el acceso a la regularización y, con ello, el acceso a derechos sociales para una gran cantidad de población. En Ecuador, también se dispuso de un sistema online para lograr la regularización específicamente de la población venezolana, el cual no ha mostrado grandes resultados, como se verá más adelante.

Más bien, la llegada de venezolanos se ha usado políticamente para legitimar el camino hacia el endurecimiento de las políticas migratorias ecuatorianas, que se trasluce en la duplicación del número de países a los cuales se requiere visado y las modificaciones proyectadas para la reforma de la ley de movilidad humana. Esta incorpora figuras como "migración riesgosa", "reciprocidad internacional", "flujos masivos provocados por crisis", "ser considerado una amenaza o riesgo para la seguridad interna", entre otras. ${ }^{37} \mathrm{El}$ tratamiento del caso venezolano en ambos países no solo contraría derechos humanos, sino que viola, por ejemplo, los acuerdos de libre residencia de Mercosur, en los cuales Argentina reconoce a Venezuela, y el estatuto migratorio entre Ecuador y Venezuela.

A continuación, se da cuenta de cómo en los países del derecho humano a migrar, los Estados han aplicado excepcionalidades a ciertos grupos migrantes, limitando el concepto mismo a través de normas de menor jerarquía y utilizando distintos planos de discrecionalidad que atentan contra los principios de igualdad y no discriminación.

\footnotetext{
${ }^{36} \mathrm{RV}_{\text {, }}$ "Plataforma de coordinación para refugiados y migrantes de Venezuela". Disponible en: https://r4v.info/es/ situations/platform

${ }^{37}$ Véase Presidencia de la República del Ecuador, "Proyecto de ley orgánica reformatoria a la ley orgánica de movilidad humana", Quito, Oficio T.068-SGJ-19-0574, 29 de julio de 2019, pp. 1-21.
} 


\section{La excepcionalidad como regla}

El reconocimiento de la migración como un derecho humano requiere de normas y políticas activas que protejan a las personas. Sin embargo, las medidas de protección muchas veces han incentivado medidas de control migratorio en Argentina y Ecuador. ${ }^{38}$ Bajo la idea de la protección, el control migratorio queda legitimado y se inserta -de manera a veces opaca-, con el pretexto de tornar los movimientos poblacionales "seguros y regulares". Ciertamente, muchas de esas medidas están acompañadas de discursos de seguridad o humanitaristas ${ }^{39}$ que tejen una relación entre "proteger para así controlar" o "controlar para proteger". Esto se inserta incluso en los pactos globales de migración y refugio de 2018.

Como sintetiza Domenech, podemos considerar que estas normas se erigen como políticas de "control con rostro humano" que, intermediadas por la legitimidad del discurso de los derechos humanos, instrumentalizan el control sobre la inmigración irregular. ${ }^{40}$ Este tipo de control, sostenemos, es diferenciado, pues crea categorías diversas para el tratamiento de quienes llegan al país, regularizando o irregularizando su permanencia en él, según momentos políticos y procedencia de los flujos.

Si bien desde el preámbulo de la Constitución argentina se considera que los derechos en el país están "para todos los hombres del mundo que quieran habitar en el suelo argentino” y en los artículos 13 y 3.f de la Ley de migraciones 25.871 se establece que en la Argentina se garantiza "el goce de criterios y procedimientos de admisión no discriminatorios en términos de los derechos y garantías", ${ }^{41}$ es necesario aclarar que los avances normativos tienen un correlato esquizofrénico en la realidad, a la hora de garantizar la permanencia legal en el país.

Podemos adelantar que, en Argentina, la política internacional y las coyunturas económicas han permeado claramente la política migratoria. Esta no es estática, y ha variado sus formas de reconocer y controlar a las personas migrantes desde hace más de un siglo. Antes, propició la migración europea ${ }^{42}$

\footnotetext{
${ }^{38}$ Courtis, Corina y Pacecca, Maria Inés, "Migración y derechos humanos: una aproximación crítica al 'nuevo paradigma' para el tratamiento de la cuestión migratoria en la Argentina", Revista Jurídica de Buenos Aires, núm. especial sobre derechos humanos, pp. 183-200.

${ }^{39}$ FASSIN, DIDIER, La razón humanitaria. Una historia moral del tiempo presente, Buenos Aires, Prometeo, 2016.

${ }^{40}$ Domenech, Eduardo, "'Las migraciones son como el agua': Hacia la instauración de políticas de 'control con rostro humano'. La gobernabilidad migratoria en la Argentina", Polis. Revista Latinoamericana, vol. 12, núm. 35, p. 2.

${ }^{41}$ Ley 25.871, Buenos Aires, 17 de diciembre de 2003, Boletín Oficial, 21 de enero de 2004.

${ }^{42}$ MAGUID, ALICIA, "La migración internacional reciente en la Argentina. Características e impacto en el mercado de trabajo", en Manuel Ángel Castillo, Alfredo Lattes y Jorge Santibáñez (coords.), Migración y fronteras, México, Colef-Somede-Colmex, 1998, pp. 25-50.
} 
y, desde 2003, reconoció la migración sudamericana, pero siempre dejando a nacionalidades por fuera del margen de lo regular. Por ello, "nada impide pensar que en el largo plazo los destinos de los flujos se modifiquen y Argentina reciba migrantes no previstos y se inicie nuevamente con ellos el circuito de vulnerabilización"43 hacia nuevas nacionalidades.

Un ejemplo ha sido el establecimiento de visados de turismo a nacionalidades como la dominicana, que no requería visa sino hasta 2012. Esta visa de turismo fue impuesta con la excusa de prevenir que las dominicanas cayeran en redes de trata de personas. En este caso, estudios posteriores demostraron que la "imposición de la visa para el ingreso como turista llevó a muchas personas a buscar caminos alternativos, más caros, probablemente peligrosos, y que además redundan en una futura imposibilidad de regularización de residencia". ${ }^{44}$

Para ingresar al país, Argentina exige visa consular a quienes portan pasaporte de unos 110 Estados, en su mayoría africanos (salvo Sudáfrica) y casi toda Asia, exceptuando a algunos países como Japón, Corea del Sur, Hong Kong, Georgia o Emiratos Árabes. Pueden entrar sin visa quienes provengan de países europeos y sudamericanos, así como personas australianas y provenientes de Nueva Zelanda. En cuanto a los centroamericanos y caribeños, se les exige visa a los de Bahamas, Belice, Cuba, Haití y República Dominicana. ${ }^{45}$

El requerimiento de visados y las restricciones para el ingreso se modificaron según los momentos políticos. Las personas haitianas, después del terremoto que azotó al país caribeño en 2010, podían ingresar como turistas a Argentina y regularizarse vía razones humanitarias, establecidas en el artículo $23 \mathrm{~m}$ ) de la Ley 25.871. En marzo de 2017, con el cambio de signo político del gobierno, se expidió la Disposición 1143- E/2017, que regularizó a quienes hubieran ingresado al país hasta el 1 de marzo de 2017. Un año y medio después, en agosto de 2018, a las personas haitianas se les impuso un visado consular. ${ }^{46}$ La imposición del visado de 2018, por medio de la Resolución 477/2018, no fue más que la cristalización de la política de control fronterizo que les fue aplicada con discrecionalidad a las personas haitianas por años.

\footnotetext{
${ }^{43}$ Pacecca, Maria InÉs, "El Mercosur y la normativa migratoria argentina (2000-2005)", en VII Congreso Nacional de Ciencia Politica de la Sociedad Argentina de Análisis Politico, Buenos Aires, 15-18 de noviembre de 2006, p. 3.

${ }^{44}$ Organización Internacional para las Migraciones, "La migración dominicana en Argentina. Trayectorias en el nuevo siglo (2000-2015)", Buenos Aires, olm-Caref, 2015, p. 31.

${ }^{45}$ PACECCA, María InÉs, "Personas, papeles, políticas y derechos: las migraciones contemporáneas en Argentina desde la perspectiva de Caref, 2004-2015", en María Inés Pacecca, Ciudad Autónoma de Buenos Aires, Caref Comisión Argentina para Refugiados y Migrantes, 2019.

${ }^{46}$ Trabalon, 2018.
} 
Los números oficiales muestran que en 2014 hubo 208 rechazos de personas haitianas en fronteras argentinas, e incrementaron a 1094 para 2018, aunque esta cifra disminuyó a unas 95 personas después de la imposición del visado consular. ${ }^{47}$ En contraposición al visado haitiano, también en 2018 se eximió a los estadounidenses de la tasa de reciprocidad ${ }^{48}$ que se pagaba a forma de visado, es decir, se les retiró el papeleo y el costo para ingresar al país.

Otro colectivo que vio mover su agenda con los vaivenes políticos fue el de las personas senegalesas, a quienes se les exige desde hace años un visado consular para ingresar al país. Una vez dentro, no cuentan con posibilidad viable de regularización. Pero, en 2013, por medio de la disposición 0002 de la DNM, se reconoció que un importante número de senegaleses habitaba el suelo argentino sin posibilidad de regularizarse por las vías establecidas. Por ello, se hizo un programa especial que les exigía adscribirse al sistema tributario como trabajadores autónomos y no tener antecedentes penales. Con este programa, muchos pudieron obtener su DNI, con la residencia temporal que debía renovarse cada doce y veinticuatro meses después de comprobar el pago del monotributo y, finalmente, a los tres años, se podía solicitar la residencia permanente. ${ }^{49}$

En ese contexto, se otorgaron unas 1600 residencias temporarias, renovando esas 1500 en 2014. Ello constituye un gran avance si pensamos que entre 2004 y 2012 solo se habían otorgado 100 residencias a senegaleses. $^{50}$ Por su parte, quienes llegaron después del programa de 2013 quedaron en el mismo limbo legal que antes de la regularización. Y, cuando la política migratoria fue modificada en 2017 por medio del DNU 70/17, estuvieron sobreexpuestos a la criminalización, debido a su irregularidad migratoria. Así, la senegalesa se convirtió en una de las nacionalidades más perseguidas en las principales ciudades argentinas, lo cual derivó en un gran aumento de las órdenes de expulsión. ${ }^{51}$

${ }^{47}$ Universidad Nacional de Lanús y Comisión para Refugiados y Migrantes de la Argentina, "Pedido de informes a la Dirección Nacional de Migraciones", 2019.

${ }^{48}$ La pagaban bajo la forma de visado de turismo.

49 Pérez Rabasa, Jeremias y Jaramillo Fonnegra, Verónica, "La criminalización de la migración y el rol de las transnacionales en los países de destino: el caso de senegaleses en Barcelona y Buenos Aires", Revista De Estudios E Pesquisas Sobre As Américas, vol. 13, núm. 1, pp. 107-139.

${ }^{50}$ Pacecca, Maria Inés; Canelo, Brenda y Belcic, Sofía, "Culpar a los negros y a los pobres. Los 'manteros' senegaleses ante los allanamientos en el barrio de Once", en María Victoria Pita y María Inés Pacecca (eds.), Territorios de control policial. Gestión de ilegalismos en la Ciudad de Buenos Aires, Buenos Aires, Editorial Facultad de Filosofía y Letras de la Universidad de Buenos Aires, 2017, p. 199-220.

${ }^{51}$ Pérez Rabasa, Jeremias y Jaramillo Fonnegra, Verónica, "La criminalización de la migración y el rol de las transnacionales en los países de destino: el caso de senegaleses en Barcelona y Buenos Aires", Revista De Estudios E Pesquisas Sobre As Américas, vol. 13, núm. 1, pp. 107-139. 
En Ecuador, la convivencia durante casi una década de los enfoques de la Constitución de 2008 y la ley de migración de 1971 ha planteado contradicciones en la aplicación de las políticas migratorias. La puesta en marcha del principio de ciudadanía universal, consagrado en la Carta Magna, posibilitó en 2008 la abolición del requerimiento de visados para estancias de hasta noventa días para todas las nacionalidades, y la concesión de igualdad de derechos en este sentido, se vio opacada por el restablecimiento posterior de este requisito para ciertos migrantes. Ello significó un retroceso para la libre circulación y los derechos civiles de algunos colectivos nacionales. ${ }^{52}$

Esgrimiendo motivos de seguridad, en 2010, se les impuso nuevamente el visado a los nacionales de Afganistán, Bangladesh, Eritrea, Etiopía, Kenia, Nepal, Nigeria, Pakistán y Somalia. En 2015, se añadió el requerimiento de visa para las personas de Senegal y Cuba. Para estos últimos, la posición oficial defendió que fue "con el fin de proteger de los abusos y las violaciones de sus derechos que pueden ser producto de una movilidad arriesgada y de traficantes sin escrúpulos". ${ }^{53}$ Dos años después, la obligación de visado se extendió a Corea del Norte.

Pero la lista de los doce países a los cuales se les exigía visado para ingresar a Ecuador se duplicó en 2019. Luego de la inclusión de Venezuela en julio, apenas un mes después, sobrevinieron once países asiáticos y africanos, tales como India, Sri Lanka, Irak, Siria, Angola, Camerún, Gambia, Ghana, Guinea, Libia y República Democrática del Congo. La decisión gubernamental se amparaba en que

Con la finalidad de garantizar una migración ordenada, regular y segura, es necesario establecer el requerimiento de visas para el ingreso al Ecuador para los nacionales de ciertos países con los cuales es menester fortalecer los mecanismos de ordenación de la movilidad humana y control migratorio (Ministerios de Relaciones Exteriores y Movilidad Humana y de Gobierno, 2019).

La migración “ordenada, regular y segura” es legitimada por el Ecuador como un atributo soberano para discriminar, a través del control restrictivo, solo a algunos flujos migratorios. El abordaje conjunto de la migración desde los

\footnotetext{
${ }^{52}$ Góngora-Mera, Manuel; Herrera, Gioconda y Muller, Conrad, "The Frontiers of Universal Citizenship. Transnational Social Spaces and the Legal Status of Migrants in Ecuador", Desigualdades, núm. 71, Berlin, Desigualdades International Research Network on Interdependent Inequalities in Latin America, 2014, pp. 1-39.

${ }^{53}$ Cancilleria de Ecuador, "Tourist Visa Requirement for Cuban citizens", 2015. Disponible en: https://www.cancilleria. gob.ec/tourist-visa-requirement-for-cuban-citizens/
} 
derechos humanos y la seguridad abrió una ventana a las posibilidades de discrecionalidad en la atención de ciertas corrientes migratorias en Ecuador. Así, es notorio el impulso que el Estado andino dio al endurecimiento de sus medidas en contra de otros flujos del hemisferio sur, luego del caso venezolano.

La apertura propuesta por Ecuador fue selectiva y casuística, conforme llegaron distintas corrientes migratorias. ${ }^{54}$ Un ejemplo puntual han sido los casos de los cubanos y haitianos. Ante el aumento de estos flujos, debido a la exención de visado turístico, Ecuador endureció los requisitos de ingreso para estos colectivos. A partir de 2013, el Estado ecuatoriano impuso a los nacionales de Cuba y Haití la obligación de presentar una carta de invitación para ingresar al país en pos de "contribuir a la vigencia de un flujo migratorio ordenado [...] e impedir el tráfico de personas". ${ }^{55}$

Este mecanismo de control presentaba exigentes requisitos, tales como el aval económico de un ciudadano ecuatoriano o extranjero regular, quien, a través su declaración de impuestos, debía realizar una declaración jurada ante un notario en la cual se comprometía a cubrir todos los gastos de alojamiento, alimentación y eventual atención médica del ciudadano cubano o haitiano durante la estadía en Ecuador. Estos requerimientos ponían en serias condiciones de desigualdad a los cubanos y haitianos frente a otros grupos migrantes, pues, con una garantía escrita, el Estado ecuatoriano se aseguraba de que no se convirtiesen en una carga.

La medida para nacionales cubanos estuvo vigente poco más de un año, hasta 2014 y, en diciembre de 2015, se impuso el visado turístico para ingresar a Ecuador. Sin embargo, a los haitianos se les complejizó aún más el ingreso a este país, debido a la imposición del "Sistema Virtual de Registro Turístico", en 2015. A través de esa herramienta -aún en uso-, el ingreso de los ciudadanos haitianos debe ser validado por el Estado ecuatoriano, previo a su arribo. Así, deben cumplimentar una serie de probanzas entre las cuales está demostrar la reservación de un hospedaje. Una muestra tomada entre 2015 y $2016^{56}$ daba

\footnotetext{
${ }^{54}$ Herrera, Gioconda y Cabezas Gálvez, Gabriela, "Ecuador: de la recepción a la disuasión. Políticas frente a la población venezolana y experiencia migratoria 2015-2018", en Luciana Gandini, Fernando Lozano Ascencio y Victoria Prieto (coords.), Crisis y migración de la población venezolana. Entre la desprotección y la seguridad juridica en Latinoamérica, México, UNAM, 2019, pp. 125-155.

${ }^{55}$ CAncilleria de Ecuador, "Ecuador requerirá carta de invitación para ingreso de ciudadanos cubanos", Boletín de prensa, núm. 014, 15 de enero de 2013. Disponible en: https://www.cancilleria.gob.ec/ ecuador-requerira-carta-de-invitacion-para-ingreso-de-ciudadanos-cubanos/

${ }^{56}$ Ortiz PInos, Dolores, "La inmigración de jóvenes haitianos a la ciudad de Cuenca y sus proyectos de vida en el marco de las políticas migratorias ecuatorianas" tesis de maestría en Migración, Derechos Humanos y Políticas Públicas, Facultad de Ciencias Económicas y Administrativas, Universidad de Cuenca, 2016. La autora considera desde agosto de 2015 a marzo de 2016.
} 
cuenta de la alta tasa de rechazos de haitianos, esta ascendía a $80 \%,{ }^{57}$ lo cual evidenciaba la instrumentalidad de esta medida.

Mientras, la Constitución ecuatoriana de 2008 reconocía el derecho a migrar y declara que ningún ser humano puede ser considerado como ilegal, también aboga por que nadie pueda ser discriminado por su condición migratoria y establece que el Estado ecuatoriano adoptará medidas de "acción afirmativa" para promover la igualdad real en favor de quienes se encuentren en situación de desigualdad. ${ }^{58}$

Citando estas fundamentaciones, en 2010, Ecuador derogó el artículo 38 de la codificación de la ley de migración de 2005 y exoneró a los ciudadanos haitianos en situación irregular de multas administrativas, argumentando que existía "la necesidad de una discriminación positiva". ${ }^{59}$ Esta excepción obedecía a un fin legítimo, que era facilitar la permanencia de esta población luego del terremoto que azotó la isla en 2010. No obstante, las condiciones de ingreso de los ciudadanos haitianos han sido notoriamente complejizadas con las medidas que hemos señalado en 2013 y 2015. En síntesis, el tratamiento de la migración haitiana, tanto en Ecuador como en la Argentina, muestra la doble faz de la discriminación positiva y negativa, en la cual la excepción se aplica como norma.

\section{La regularización en épocas de derechos humanos}

Aunque la regularización migratoria está lejos de ser una medida represiva, pone a prueba el poder estatal y debe ser entendida como un mecanismo de control para regular la inmigración, particularmente aquella que se construye como "ilegal". ${ }^{60}$ Pero, además, esta regularización es la puerta de ingreso a derechos civiles, políticos, económicos, sociales y culturales. Es una herramienta que identifica y da reconocimiento jurídico en el nuevo territorio a quienes hacen parte de él. Este reconocimiento puede establecerse para permanecer

\footnotetext{
${ }^{57}$ ORTIZ PINOS, Dolores, "La inmigración de jóvenes haitianos a la ciudad de Cuenca y sus proyectos de vida en el marco de las políticas migratorias ecuatorianas" tesis de maestría en Migración, Derechos Humanos y Políticas Públicas, Facultad de Ciencias Económicas y Administrativas, Universidad de Cuenca, 2016.

${ }^{58}$ Constitución de la República del Ecuador, 2008, art. 11.

${ }^{59}$ Ley derogatoria del art. 38 de la Ley de Migración, y de exoneración económico tributaria a favor de los ciudadanos haitianos que ingresaron al Ecuador hasta el 31 de enero de 2010 y se hallan actualmente en situación irregular en el territorio ecuatoriano, Quito, Asamblea Nacional, 11 de marzo de 2010, p. 2.

${ }^{60}$ DomeneCH, EduARDo, "Crónica de una 'amenaza' anunciada. Inmigración e 'ilegalidad': visiones de Estado en la Argentina contemporánea", en Bela Feldman-Bianco; Liliana, Rivera Sánchez; Carolina, Stefoni y Marta Inés Villa Martínez (comps.), La Construcción del sujeto migrante en América Latina: Prácticas, representaciones y categorias, Quito, Flacso-Clacso-Universidad Alberto Hurtado, 2011, p. 60.
} 
en el país por un corto o largo periodo e incluso -cuando se tiene protección internacional, como refugiado o apátrida- por tiempo indeterminado.

Para poder generar políticas públicas de cualquier tipo, los Estados deben adentrarse en la situación de las personas que habitan su territorio; de ahí la importancia de conocer y censar a sus poblaciones, sin importar su origen o su estatus migratorio. Sin embargo, es la regularización la que permite el ejercicio del derecho humano a migrar, porque es a partir de la documentación local que se puede acceder y exigir derechos con las limitaciones de cada caso. En definitiva, se dota de contenido al derecho humano a migrar a partir de la regularización.

Por otra parte, el derecho a la regularización cobra sentido desde el derecho a la personalidad jurídica, el cual ha sido ha reconocido por la Corte Interamericana en el caso "Personas Dominicanas", donde se sostuvo que el desconocimiento de la documentación por parte del Estado afecta el derecho a la personalidad jurídica y se definió esta posibilidad de tener derechos y obligaciones; en la cual el Estado debe arbitrar los medios para que este reconocimiento pueda ser ejercido, por cuanto es él el que "determina la existencia efectiva ante la sociedad y el Estado" ${ }^{61}$.

\section{La regularización en la Argentina}

Después de que entrara en vigencia la ley de migraciones en 2004, uno de los grandes desafíos de Argentina era regularizar y documentar a una gran cantidad de población migrante que habitaba el país de manera administrativamente irregular, y que era excluida de los sistemas de salud, educación y demás servicios sociales. Para subsanarlo, en el año 2004, se declaró una emergencia administrativa por decreto ejecutivo, 836/04, y al año siguiente se rubricó su continuación con el 578/05, donde se autorizó iniciar un plan de regularización. ${ }^{62}$

Igualmente, en 2005, se dictó la Disposición 53253 (13/12/2005), con la cual se implementó el Programa Nacional de Normalización Documentaria Migratoria para ciudadanos de países del Mercosur y países asociados, al cual

\footnotetext{
${ }^{61}$ GarciA, LIAA, "Migraciones, Estado y una política del derecho humano a migrar: ¿hacia una nueva era en América Latina?", Colombia Internacional, núm. 88, p. 121.

${ }^{62}$ Modolo, VAnINA, "Movilidad territorial en el Mercado Común del Sur. La construcción del residente mercosureño y el Estado argentino (1991-2012)", tesis de doctorado en Ciencias Sociales, Facultad de Ciencias Sociales, Universidad de Buenos Aires, 2013.
} 
se le conoce como "Patria Grande". ${ }^{63}$ Dicho programa reconoció, no como amnistía, sino como política permanente del Estado ${ }^{64}$ la posibilidad de obtener documentación ${ }^{65}$ para quienes trabajaban y vivían en la República Argentina. Pero fue a partir de junio de 2008 que se reconoció el criterio de nacionalidad Mercosur para otorgar los trámites de residencia. ${ }^{66}$

El "Patria Grande", en principio, constituyó un gran avance en materia de regularización migratoria para ciudadanos mercosureños, quienes equivalen a la gran mayoría de las personas migrantes del país. Pero también presentó algunos problemas estructurales. Algunas personas no contaban con el dinero necesario para regularizar su situación y no conocían la posibilidad de realizar el trámite con un certificado de pobreza que los eximía de abonarlo. ${ }^{67}$ Además, algunos funcionarios públicos interpusieron límites discrecionales que, en ocasiones, generaron el vencimiento de los términos, y tales retrasos dilataron la obtención del documento nacional de identidad (DNI) por tiempos muy prolongados. Es decir, los funcionarios encargados de dar la atención a los y las migrantes tardaron mucho en estar sensibilizados, mientras los migrantes permanecieron desinformados.

En los peores casos, a algunas personas se les cursaron órdenes de expulsión por no haber cumplido con los requisitos documentarios. La mayoría de esas órdenes nunca fueron ejecutadas, ni tampoco había una política activa de persecución por parte del Estado que generase redadas o riesgos de separación de familias. No obstante, esta situación de irregularidad terminó por confınar a las personas migrantes a espacios laborales "confiables", donde frecuentemente eran sometidos a la explotación y al aislamiento.

Pasaron años antes de que se empezara a evidenciar el impacto de estos programas de regularización, los cuales tuvieron un aumento en el número

\footnotetext{
${ }^{63}$ COURTIS, CoRina y PACECCA, MaRía InÉs, "Migración y derechos humanos: una aproximación crítica al 'nuevo paradigma' para el tratamiento de la cuestión migratoria en la Argentina", Revista Jurídica de Buenos Aires, núm. especial sobre derechos humanos, pp. 183-200.

${ }^{64}$ DomeneCH, EDUARDO, "La ciudadanización de la política migratoria en la región sudamericana: vicisitudes de la agenda global", en Susana Novick (comp.), Las migraciones en América Latina. Políticas, culturas y estrategias, Buenos Aires, Catálogos-Clacso, 2008, pp. 53-72.

${ }^{65}$ Cerrutti, Marcela, "Gender and Intra-Regional Migration in South America", Human Development Research Paper, núm. 12. Disponible en: https://mpra.ub.uni-muenchen.de/19192/1/MPRA_paper_19192.pdf

${ }^{66}$ Modolo, Vanina, "Movilidad territorial en el Mercado Común del Sur. La construcción del residente mercosureño y el Estado argentino (1991-2012)", tesis de doctorado en Ciencias Sociales, Facultad de Ciencias Sociales, Universidad de Buenos Aires, 2013.

${ }^{67}$ Centro de Estudios Legales y Sociales, Informe anual sobre la situación de los derechos humanos en Argentina, Buenos Aires, Siglo XXI, 2007.
} 
de las resoluciones de residencias permanentes y temporarias ${ }^{68}$ y garantizaron una mayor celeridad y transparencia en el proceso. Con el paso del tiempo, el trabajo del Estado se fue tecnificando y haciendo más eficiente en la regularización de la población de la región. En esto tuvo mucho que ver el contexto de integración regional que se vivía por esos años, porque quienes se beneficiaban especialmente de estos programas de regularización eran personas de origen sudamericano.

Las cifras oficiales entre 2004 y el primer semestre de 2015 indican que se iniciaron, en total, 2332389 solicitudes en las diferentes categorías de residencia, de las cuales fueron resueltas un total de 2158601 radicaciones en todo el país. ${ }^{69}$ De estas radicaciones resueltas, 88\% (1 870 194) se dio durante el periodo 2008-2015, ${ }^{70}$ tras la implementación del Programa de Abordaje Territorial, el cual asistía a distintos territorios alejados de los centros urbanos. Su finalidad era documentar y llevar información a poblaciones de escasos recursos, que, luego de varios años de sancionada la ley, desconocían sus derechos.

El trámite para la regularización migratoria se iniciaba solicitando un turno en la página web de la DNM para acudir de forma presencial a llevar la documentación. Ese turno podía tardar entre uno y dos meses en hacerse efectivo y, en épocas de mayor demanda, hasta cuatro meses. Acudiendo al turno presencial, se debía mostrar la documentación requerida y pagar las tasas correspondientes en el día asignado. Para el pago había ventanillas habilitadas dentro de la propia oficina, para no tener que salir del edificio.

Si el migrante no disponía de medios para pagar las tasas debía llevar un certificado de la condición de vulnerabilidad el mismo día del turno, el cual

\footnotetext{
${ }^{68}$ Ley 25.871 de migraciones, Buenos Aires, 17 de diciembre de 2003, Boletín Oficial: 21 de enero de 2004, art. 23. En la Argentina, a partir de la Ley 25.871 , se puede solicitar la regularización migratoria a través de dos categorias de residencia temporaria, que duran entre uno y tres años, según la categoría, y se otorga a personas que se acrediten como rentistas, pensionados, inversionistas, científicos, deportistas, artistas, religiosos de cultos reconocidos oficialmente, pacientes bajo tratamiento médico, académicos, estudiantes, asilados, refugiados, trabajadores migrantes con contrato de trabajo, y ciudadanos nativos de Estados parte del Mercosur o asociados. Para su radicación, las personas migrantes del Mercosur requieren acreditar mediante documentación vigente; carecer de antecedentes penales en Argentina y en otros paises donde hayan vivido más de un año; contar con sello de ingreso al pais (lo cual se constituye como prueba de ingreso regular al pais) y presentar un certificado de domicilio en Argentina. En tanto, las personas extra-Mercosur solo pueden solicitar la regularización bajo la categoria estudiante o trabajador con contrato de trabajo y se les exige que las entidades educativas o empresas por las cuales se presentan formen parte de un registro único de requirentes (Renure), además de la inscripción a la agencia tributaria AfIP con copias certificadas por notario público, lo cual acarrea altos costos. Igualmente, deben alegar una constancia de inscripción y un contrato de trabajo que acredite los extremos de la relación laboral.

${ }^{69}$ DiRección Nacional de Migraciones, Panorama radicaciones 2011-2015, 2015a. Disponible en: http://www.migraciones. gov.ar/pdf_varios/estadisticas/radicaciones_2011-2015.pdf.

${ }^{70}$ Centro de Estudios Legales y Sociales, Informe anual sobre la situación de los derechos humanos en Argentina, Buenos Aires, Siglo XXI, 2017.
} 
conseguía a través de distintas oficinas del Estado, organizaciones no gubernamentales o trabajadores sociales. Si la persona migrante carecía de alguna documentación, se le asesoraba en esa misma oportunidad en las oficinas de la DNM. Entregada toda la documentación, se recibía un certificado de residencia precaria. El comprobante de trámite en curso le permitía acceder a un número de identificación laboral (cuiL) para trabajar en forma regular. En un lapso entre 30 y 45 días, llegaba el DNI por correo, a la puerta de la casa o a las oficinas de delegaciones cercanas, en caso de que fueran barrios carenciados sin nomenclador.

Para 2015, con la llegada de un gobierno de corte conservador, los planes de regularización comenzaron a variar. Esta situación coincidió con la crisis venezolana que atravesaba toda la región y fue una de las excusas que aducian las autoridades migratorias para el cambio en el sistema de regularización. El primer gran cambio tuvo que ver con el fin de los programas de abordaje territorial, los cuales habían tenido gran repercusión en el aumento de las residencias. Por otra parte, se dio un elevado aumento de las tasas migratorias entre 500 y 700\% ${ }^{71}$ y, para finales de 2018, lanzó un sistema online para los trámites migratorios.

Entre 2016 y 2017, el sistema de turnos presenciales se había hecho extremadamente lento, obtener uno podía tardar entre seis meses y un año. El cierre de algunas delegaciones y el recorte del servicio a media jornada en la DNM hizo que se congestionara el sistema. Las autoridades esgrimían que, por el gran incremento de personas de origen venezolano, el sistema no daba abasto.

Las cifras dadas por la propia DNM sí evidenciaban un aumento considerable del flujo de venezolanos, pero en contraposición a una disminución de antiguos flujos de países vecinos como Paraguay, Bolivia y Perú, pues en Argentina se vivía un momento económico difícil que lo hizo menos atractivo para los habitantes de estos países. ${ }^{72}$ Es decir, no existía un número mayor de migrantes en el país, lo que había cambiado era el país de procedencia.

En este contexto se dio el lanzamiento del sistema de radicación a distancia de extranjeros (Radex), bajo la consigna de agilizar las solicitudes y trámites migratorios. Entre sus objetivos principales estaba eliminar el sistema de trámites presenciales. Pero, contrario a su razón de ser, el Radex complicó

\footnotetext{
${ }^{71}$ Autor/a; Gll Araujo, Sandra; Rosas, Carolina, "Control migratorio y producción de irregularidad. Normas, prácticas y discursos sobre la migración en la Argentina de Cambiemos", Forum. Revista Departamento de Ciencia Política, en prensa.

72 PaceCcA, Maria Inés y ChaivetTa, VAleria, El dnI ¿más lejos o más cerca? Regularización y documentación de migrantes a través del sistema Radex, Buenos Aires, Observatorio sobre Migraciones y Asilo en Argentina "Gabriel Chausovsky", 2020. Disponible en: https://drive.google.com/file/d/139zi0E1zVfola8IwhZNA8Mu_AgiGRRoU/view
} 
el sistema de documentación. En principio, toda la solicitud y la carga de la documentación se realizaba online; para iniciar el trámite, es necesario tener un correo electrónico y pagar la tasa migratoria. Posteriormente, la persona migrante tenía un plazo de treinta días para obtener y cargar toda la documentación requerida. Si el migrante no lo hacía dentro de este plazo, perdía tasa ya pagada y debía reiniciar el trámite.

Una de las grandes fallas del sistema era que al cargar toda la documentación no se recibía ningún comprobante de inicio de trámite en línea. Esto podía repercutir negativamente, en caso de que se tuviera que demostrar la condición regular y probar el inicio de trámite ante la autoridad migratoria. Cuando la documentación estaba completa y aprobada por la plataforma, el migrante debía concurrir, como en el sistema anterior, a la oficina con los documentos cargados e inscribir sus huellas digitales, fotos y demás.

Otro problema fue que las poblaciones que no hablaban castellano quedaron fuera del sistema y no contaban con opciones reales para regularizarse. Si el migrante no podía pagar la tasa, no iniciaba el trámite online y, por lo tanto, debía ir presencialmente a las oficinas de Migraciones. Los trámites que antiguamente eximían del pago eran "cartas de vulnerabilidad" que se podían realizar en distintos organismos del Estado, pero, en épocas de Radex, solo se tramitan para cuarenta personas por día, en la sede central de la DNM.

Por tanto, aquello que pretendía ser un sistema de agilización en línea, lo único que logró fue burocratizar y garantizar el pago de las tasas antes de iniciar cualquier tipo de trámite. Además, en las oficinas de la DNM no se proporcionaron elementos como computadoras, impresoras o escáneres para que las personas migrantes pudieran realizar su trámite dentro de la sede del organismo público con acompañamiento de sus funcionarios. Por ello, la persona migrante solo podía concurrir con dudas puntuales, pero sin la posibilidad de realizar el trámite en la propia oficina con asesoría directa.

En sintesis, el Radex supuso nuevas y numerosas barreras de acceso a la regularización, por las cuales el sistema es discriminatorio y excluyente, especialmente para las personas socioeconómicamente vulnerabilizadas. Por un lado, el sistema requiere de acceso permanente a un dispositivo electrónico para iniciar y avanzar en el trámite; por otro lado, la persona debe contar con el capital social y cultural ${ }^{73}$ que le brinde conocimientos informáticos para comprender el sistema y poder cargar la documentación, además de hacer el seguimiento en línea de su trámite.

${ }_{73}$ Bourdieu, PierRe, La dominación masculina, Barcelona, Anagrama, 2000. 
Después de un año de implementación había más dudas que certezas de cómo debía finalmente realizarse el trámite y sobre su efectividad. Esta situación favoreció la aparición de figuras como los gestores, cuyo rol histórico ha tendido a socavar los derechos de las personas migrantes y a involucrar a agencias públicas en prácticas de dudosa legalidad.

En cifras concretas, después de la aparición del Radex, 2019 fue el año en que menos radicaciones definitivas hubo en el país, desde 2004. Así, se otorgaron unas 130000 residencias, mientras que, entre 2004 y 2018, se mantuvieron estables por encima de las $200000 .^{74}$ Estos números demuestran el fallo del sistema y la intencionalidad de un gobierno de irregularizar a su población migrante, como afirmó la actual directora nacional de Migraciones, Florencia Carignano: "lo que [...] veíamos como un gran problema era el Radex, este sistema que básicamente impedía que la gente pueda acceder a un estatus migratorio que le corresponde y que tenía derecho y [así] regularizar su situación migratoria". ${ }^{75}$ Este sistema de regularización se aplica especialmente a las personas provenientes de países del Mercosur, pero incluye límites más claros para nacionalidades que no pertenecen.

Paralelamente al funcionamiento del sistema, para 2017, el gobierno expidió un Decreto de Necesidad y Urgencia (DNU) el 70/17, que modificó drásticamente los procedimientos de expulsión del país. Creó un mecanismo sumarísimo para que, en tres días, la persona pudiera ser expulsada, pero además limitó el sistema de notificaciones y el derecho de defensa. Además, la norma eliminó el principio de inocencia para las personas migrantes, pues quien se viera inmiscuido en cualquier investigación podría encarar un proceso de expulsión con la mera instrucción de un fiscal.

Entre la implementación del Radex y el DNU 70/17, la política migratoria argentina tuvo, en tres años, un gran revés, con un aumento de 350\% de las expulsiones $^{76}$ de personas que infringieron la norma migratoria, por estar en situación administrativa irregular, es decir, sin cometer delito alguno. Esta norma contraria a derechos humanos, a más de siete meses de la llegada de

\footnotetext{
${ }^{74}$ PACECCA, María INÉS, "Personas, papeles, políticas y derechos: las migraciones contemporáneas en Argentina desde la perspectiva de Caref, 2004-2015", en María Inés Pacecca, Ciudad Autónoma de Buenos Aires, Caref Comisión Argentina para Refugiados y Migrantes, 2019.

${ }^{75}$ Migración y AsILo IJDHUn, "Diálogo con la Directora Nacional de Migraciones, Florencia Carignano, coordinado por Pablo Ceriani Cernadas, director de la Especialización en Migración y Asilo, Instituto de Justicia y Derechos Humanos (IJDH), Universidad Nacional de Lanús, Buenos Aires", 18 de junio, 2020. Recuperado de: facebook.com/ migracionIJDHUNLa.

${ }^{76}$ Universidad Nacional de Lanús, "¿Regresividad en Derechos Humanos? El Decreto de Necesidad y Urgencia 70/17 y su impacto en el acceso a la justicia de las personas migrantes frente a los procedimientos de expulsión y detención", pedido de informes realizado en el marco del Proyecto Oscar Varsavsik, 2018.
} 
un nuevo gobierno, sigue plenamente vigente, a pesar de que el tribunal de segunda instancia declaró su inconstitucionalidad.

Con la llegada de la pandemia por covid-19, la población migrante en la Argentina enfrenta nuevos desafíos: el cierre de las oficinas y delegaciones de la Dirección Nacional de Migraciones y la suspensión de los operativos móviles de regularización, que se habían reiniciado con la llegada del nuevo gobierno en diciembre de 2019. Estas situaciones evidenciaron la cantidad de personas sin regularizar que había dejado el Radex y, en consecuencia, también expuso la enorme precariedad laboral de quienes estaban sin documentación en el país. Todas estas personas que no habían obtenido una regularización migratoria no pudieron entrar en los planes estatales de contención de la emergencia, que iban desde cajas de alimentos, subsidios habitacionales (para personas que se quedaron sin hogar) al cobro del ingreso familiar de emergencia (IFE).

El entrante gobierno tomó medidas, como la Disposición 1904/2020, para otorgar el certificado electrónico de residencia precaria, utilizando la misma plataforma del Radex. Esto permitió la regularización en línea y, al momento de formalizar la solicitud de residencia, habilitó a la persona peticionante a trabajar o realizar tareas remuneradas en forma inmediata, pudiendo también usufructuar la totalidad de los beneficios contenidos en dicho estatus migratorio.

También para tramitar este certificado se requería, no solo del pago en línea del trámite, sino de los conocimiento tecnológicos para iniciarlo. Además, se dictó la Disposición DNM 1714/2020, donde se dispuso la prórroga de los vencimientos de residencias temporarias, transitorias y precarias, así como la suspensión de plazos administrativos.

\section{La regularización en Ecuador}

Por su parte, en Ecuador, las regularizaciones recientes iniciaron con una disposición transitoria contenida en la Ley de Extranjería de 1971, que estipulaba la amnistía para los inmigrantes que no tuviesen documentos en regla, bajo apercibimiento de deportación para quienes no regularizasen su situación.

Con el correr de los años, se llegó a acuerdos bilaterales para corrientes migratorias de países vecinos. En 1982 y 1990, el país andino estableció acuerdos para regularizar la permanencia de migrantes provenientes de Colombia, mientras ocurrió lo mismo en 1998 y en 2006 para personas migrantes peruanas.

Siguiendo estos antecedentes, Ecuador inició la negociación y activación de estatutos migratorios permanentes con distintos países. En 2000, se negoció el Estatuto Migratorio Permanente entre Ecuador y Colombia, vigente recién 
en 2010, el cual garantiza facilidades para la regularización de migrantes. En tanto, en 2008, se firmó un Estatuto Migratorio Permanente EcuatorianoPeruano, en vigor desde 2011, con base en el principio de que no existen seres humanos ilegales y abogando por la no criminalización ni penalización de la migración irregular.

Estos principios basados en los derechos humanos volvieron a citarse en el Estatuto Migratorio entre Ecuador y Venezuela de 2010. El acuerdo, realizado en otro contexto histórico - pues se dio años más tarde-, posibilitó la regularización de los flujos venezolanos que llegaron antes de la aprobación de la ley de movilidad humana ecuatoriana en 2017. Estos instrumentos se activaron luego de la última Constitución, solo para ciertos flujos en un contexto regional de integración del que Ecuador era parte activo.

Este fue el marco para expedir 27224 visas a venezolanos entre 2013 y 2016, de las cuales unas 13000 se ampararon en el mencionado estatuto bilateral, siendo las más solicitadas en comparación con las demás categorías. ${ }^{77}$ Además, los nacionales de ambos países podían ingresar con fines turísticos por noventa días, sin necesidad de visado. Respecto a la residencia, la no presentación de un contrato laboral para postular a la llamada visa convenio, la posibilidad de renovar la residencia temporal por un total de cuatro años, y la agilización que suponía la posibilidad de extenderla al grupo familiar, alentaron las solicitudes de radicación de ciudadanos venezolanos en Ecuador, a través de este estatuto. ${ }^{78}$

Luego de 2017, las personas venezolanas han podido regularizar su situación a través de la llamada visa Unasur. ${ }^{79}$ Venezuela, al no ser signataria del Acuerdo sobre residencia para nacionales de los Estados Partes del Mercosur, careció de las facilidades de ingreso a Ecuador para sus ciudadanos, a diferencia de otros países sudamericanos. ${ }^{80}$ A ello se le sumó la suspensión de Venezuela en el Mercosur en 2016 y, en 2006, su retirada de la Comunidad Andina de Naciones (CAN), también integrada por Ecuador.

\footnotetext{
${ }^{77}$ Ramirez, Jacoues; Linárez, Yoharlis y Useche, Emilio, "(Geo)políticas migratorias, inserción laboral y xenofobia: migrantes venezolanos en Ecuador", en Cécile Blouin (ed.), Después de la llegada. Realidades de la migración venezolana, Lima, Themis-PucP, 2019, pp. 1-29.

${ }^{78}$ Ramirez, Jacoues; Linárez, Yoharlis y Useche, Emilio, "(Geo)políticas migratorias, inserción laboral y xenofobia: migrantes venezolanos en Ecuador", en Cécile Blouin (ed.), Después de la llegada. Realidades de la migración venezolana, Lima, Themis-PuCP, 2019.

${ }^{79}$ Herrera, Gioconda y Cabezas Gálvez, Gabriela, "Ecuador: de la recepción a la disuasión. Políticas frente a la población venezolana y experiencia migratoria 2015-2018", en Luciana Gandini, Fernando Lozano Ascencio y Victoria Prieto (coords.), Crisis y migración de la población venezolana. Entre la desprotección y la seguridad jurídica en Latinoamérica, México, unam, 2019, pp. 125-155.

${ }^{80}$ Ramirez, Jacoues; Ceja, Iréri; Coloma, Soledad y Arteaga, Romina, "'Ha, usted viene por la visa Mercosur': Migración, integración y refugio en Ecuador", Quito, Celag, 2017.
} 
El principal mecanismo que implementó el Estado ecuatoriano para regularizar a la población inmigrante fue la ejecución del acuerdo de residencia del Mercosur, ratificado por Ecuador en 2013. Con ello, expidió 33846 residencias de carácter temporal solo entre 2014 y 2016, siendo de origen colombiano más de $80 \%$ de los beneficiarios. ${ }^{81}$

Además, el impulso estatal de campañas de información para que los ciudadanos sudamericanos regularicen su condición migratoria es una de las disposiciones generales de la ley de movilidad humana ecuatoriana sancionada en 2017. En ese sentido, esta normativa plantea un trato diferencial para ciertos migrantes, pues considera "ciudadanos sudamericanos" solo a quienes pertenezcan a países de la Unión de Naciones Suramericanas (Unasur). Esta definición se ha convertido en anacrónica debido a que, actualmente, solo Uruguay, Guyana, Surinam y Venezuela permanecen en la Unasur, luego de la desvinculación entre 2018 y 2019 de Argentina, Brasil, Chile, Colombia, Paraguay, Perú, Bolivia e incluso del mismo Ecuador.

Esto tiene implicaciones directas en los "beneficios" que plantea la ley para las personas sudamericanas, por ejemplo, la imposibilidad de ser inadmitidas o deportadas en el caso de reingresar a Ecuador, mientras su proceso de regularización en curso no sea resuelto, así como la excepción del pago de multas por condición migratoria irregular, mientras se encuentren tramitando su solicitud de residencia temporal o permanente.

Un problema que se presenta para los ciudadanos sudamericanos es cumplir con el requisito de demostrar "medios de vida lícitos en el país" para regularizar su permanencia en Ecuador. Esta obligación no estaba presente en la legislación anterior y, al ser un concepto jurídico indeterminado, está sometido a la discrecionalidad del actor público. ${ }^{82}$ Asimismo, esto puede tornarse en un escollo para quienes pretenden acceder a una visa por tener hijos ecuatorianos o quienes poseen lazos de parentesco con personas ecuatorianas. De este modo, se contravienen el principio de unidad familiar y el principio del interés superior del niño. ${ }^{83}$

\footnotetext{
${ }^{81}$ Ramirez, Jacoues; Ceja, Irérl; Coloma, Soledad y Arteaga, Romina, "'Ha, usted viene por la visa Mercosur': Migración, integración y refugio en Ecuador", Quito, Celag, 2017.

${ }^{82}$ Coalición POR las Migraciones y el Refugio, Informe alternativo sobre el cumplimiento de la Convención de Naciones Unidas de los derechos de todos los trabajadores migratorios y sus familiares (ctmF), Quito, Coalición por las Migraciones y el Refugio, 2017.

${ }^{83}$ Coalición POR las Migraciones y el Refugio, Informe alternativo sobre el cumplimiento de la Convención de Naciones Unidas de los derechos de todos los trabajadores migratorios y sus familiares (стмF), Quito, Coalición por las Migraciones y el Refugio, 2017.
} 
Otro punto saliente de la nueva ley migratoria ecuatoriana es que sustituye la detención de extranjeros ${ }^{84}$ por las "salidas voluntarias" o por un oneroso sistema de multas. La ley tipifica que, de no haber regularizado su situación, el migrante será notificado por la autoridad de control migratorio de la obligación de salir del país en un plazo de treinta días y, de no cumplirse, se le iniciará un procedimiento de deportación. ${ }^{85} \mathrm{~A}$ estos se les llama "casos de salida voluntaria": la expulsión arriba de todas formas, solo que en diferentes plazos temporales.

Por otra parte, la persona extranjera que no haya regularizado su condición migratoria puede ser multada. Las multas también se imponen a extranjeros que realicen actividades diferentes a las permitidas por su visa o categoría migratoria. En caso de que exista reincidencia, peligran de que se les cancele la condición migratoria. Estos ejemplos dejan ver que, en Ecuador, el derecho humano a migrar se presenta como altamente reglado y limitado, con ingresos burocráticamente vallados para las nacionalidades extra-Mercosur. Así, se trasluce una constante de los últimos doce años: los límites a la letra de la Constitución están dados por instrumentos jurídicos de menor rango.

El reglamento de la ley de movilidad humana de 2017 esclarece en qué casos se contemplan las multas. Los residentes temporales pueden ser multados si se ausentan de Ecuador por más de noventa días en el año. Otra falta migratoria corre para los residentes permanentes que hayan superado los días permitidos para permanecer fuera del país, bajo riesgo de perder su condición migratoria en caso de reincidencia.

También existen multas para los ciudadanos sudamericanos que hayan superado los 180 días por turismo sin regularizar su condición migratoria. En esta dirección, una cláusula para prevenir que los turistas se conviertan en potenciales migrantes establece que los extranjeros que estuvieron dentro de los límites de noventa días o 180 días (lo que supone que obtuvieron una prórroga para su estancia) no podrán ingresar a Ecuador, sino hasta después de seis meses, para el primer caso, y nueve meses, para el segundo, a menos que sea a través de una visa consular.

\footnotetext{
${ }^{84}$ Durante varios años, bajo la anterior ley de 1971, en Quito existieron centros temporales para la detención de extranjeros que esperaban la resolución de su trámite de deportación. El primero fue el llamado Hotel Hernán, que estuvo en funcionamiento entre 2011 y 2013; en su reemplazo, se estableció el llamado Hotel Carrión, de 2013 a 2017.

${ }^{85}$ Ley Orgánica de Movilidad Humana, de 5 de enero de 2017, que regula el ejercicio de derechos, obligaciones, institucionalidad y mecanismos vinculados a las personas en movilidad humana, Quito, Registro Oficial (Suplemento), 6 de febrero, 2017, núm. 938, art. 142.
} 
La Coalición por las Migraciones y el Refugio ${ }^{86}$ ha alertado en un informe acerca de preocupantes aspectos sobre derechos humanos que presenta la nueva legislación migratoria. Entre ellos se encuentra la propia definición de persona extranjera, cercándola exclusivamente a quien posea la condición migratoria de visitante temporal o residente. Por lo tanto, solo considera a aquellos extranjeros regularizados, lo cual podría conllevar interpretaciones restrictivas en el ejercicio de derechos.

Esa agrupación señala otro aspecto que atenta contra el principio de igualdad y no discriminación, es la obligación que se impone solo a personas extranjeras de contar, por ley, con un seguro de salud público o privado, lo cual ha ocasionado a los migrantes problemas para regularizarse. Además, la Coalición por las Migraciones y el Refugio ha reseñado que las categorías migratorias de la nueva normativa mantienen el principio de selectividad e imposibilitan la regularización, debido a los requisitos y costos. Las dificultades en el acceso a los visados obstruyen el ejercicio de derechos en condiciones de igualdad. Por ende, se empuja a la clandestinización de los migrantes frente al control migratorio y a la posibilidad de deportación $;{ }^{87}$ pero además confinándolos a espacios laborales irregulares y a una exclusión en sus derechos sociales.

Un caso de discrecionalidad ha sido el tratamiento reciente de la migración venezolana. A raíz del aumento de los flujos venezolanos hacia Ecuador, en agosto de 2018, el país andino declaró el estado de emergencia en tres provincias, activando así mecanismos para la atención humanitaria. Ese mismo mes, mediante un oficio, el ministro de Interior ecuatoriano, Mauro Toscanini, requirió al ministro de Relaciones Exteriores que "se establezcan los lineamientos, directrices e instrumentos técnicos de gestión en el ámbito de la movilidad humana, para la ejecución del control migratorio, con el fin de garantizar la protección y promoción de derechos", advirtiendo en un informe sobre la creciente tendencia de ingreso a Ecuador con el documento nacional de identidad venezolano, el cual no presenta dispositivos de seguridad. Asimismo, expuso que ello:

\footnotetext{
${ }^{86}$ Coalición POR las Migraciones y el Refugio, Informe alternativo sobre el cumplimiento de la Convención de Naciones Unidas de los derechos de todos los trabajadores migratorios y sus familiares (ctmF), Quito, Coalición por las Migraciones y el Refugio, 2017.

${ }^{87}$ Coalición POR las Migraciones y el Refugio, Informe alternativo sobre el cumplimiento de la Convención de Naciones Unidas de los derechos de todos los trabajadores migratorios y sus familiares (стмF), Quito, Coalición por las Migraciones y el Refugio, 2017.
} 
Podría impactar negativamente en la capacidad nacional de prevención, control y protección de estos fenómenos, afectando los derechos de las personas en movilidad, y generando ambientes propicios para el fenómeno de delitos asociados a la movilidad humana, por lo que es necesario se establezcan políticas que permitan prevenir la migración irregular y riesgosa. ${ }^{88}$

Escudándose en estas motivaciones, desde el 18 de agosto de 2018, se estableció el requisito de ingreso a Ecuador con pasaporte, ${ }^{89}$ específicamente para las personas venezolanas, a excepción de niños, niñas y adolescentes. Días más tarde, se reabrió la posibilidad de utilizar la cédula de identidad, ${ }^{90}$ pero añadiendo un certificado oficial de validez.

Estas decisiones políticas del Gobierno ecuatoriano, expresadas a través de acuerdos ministeriales, han obstruido el derecho a migrar de los venezolanos, su libertad de tránsito y su acceso a la ciudadanía universal, todas cuestiones resguardadas en la Carta Magna. No conforme con esos requisitos, en enero de 2019, se impuso la presentación de un certificado de antecedentes penales apostillado o legalizado para los nacionales venezolanos. Este cúmulo de requerimientos ha afectado las posibilidades de regularidad de los migrantes de ese origen, debido a que no son documentos de ágil expedición en Venezuela.

Como anticiparon Ramírez, Linárez y Useche, ${ }^{91}$ estas nuevas medidas no solo violan la normativa ecuatoriana, sino que, en la práctica, convirtieron a Ecuador en un "Estado tapón". ${ }^{92}$ Esto cobra mayor peso si se considera que, desde julio de 2019, se da la sanción de una amnistía migratoria específica para venezolanos que se encuentren en condición irregular, pero hayan ingresado regularmente a Ecuador, así como de la creación de una visa de residencia temporal de excepción por razones humanitarias (visa Verhu).

Las medidas previstas para la implementación de esta regularización excepcional supusieron un censo de migrantes venezolanos, mientras la visa Verhu

\footnotetext{
${ }^{88}$ Ministerio de Relaciones Exteriores y Movilidad Humana, Acuerdo Ministerial núm. 242, Quito, 16 de agosto, 2018, pp. 2-3.

${ }^{89}$ Herrera, Gloconda y Cabezas Gálvez, Gabriela, "Ecuador: de la recepción a la disuasión. Políticas frente a la población venezolana y experiencia migratoria 2015-2018", en Luciana Gandini, Fernando Lozano Ascencio y Victoria Prieto (coords.), Crisis y migración de la población venezolana. Entre la desprotección y la seguridad jurídica en Latinoamérica, México, uNAM, 2019, pp. 125-155. Días después, esta medida fue revocada por un juzgado de la ciudad de Quito, gracias a las medidas cautelares interpuestas por la Defensoría del Pueblo de Ecuador.

${ }^{90}$ Este documento históricamente había sido permitido gracias a los acuerdos de la Can.

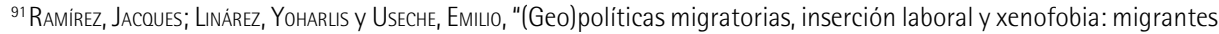
venezolanos en Ecuador", en Cécile Blouin (ed.), Después de la llegada. Realidades de la migración venezolana, Lima, Themis-PucP, 2019, p. 12.

${ }^{92}$ Este concepto en los estudios migratorios remite a Estados que, a través de sus políticas o prácticas, operan como barrera para el movimiento migratorio hacia otros paises.
} 
creó una barrera para los venezolanos en tránsito que ahora necesitan este visado para pasar por territorio ecuatoriano. Por eso, se podía postular a la visa Verhu estando ya en el país andino en situación irregular - pero habiendo ingresado por pasos fronterizos oficiales antes del 26 de agosto de 2019- o bien, desde el exterior, a través de los consulados ecuatorianos en Caracas (Venezuela), Bogotá (Colombia) y Lima (Perú). Cabe señalar que tales ciudades son el corredor habitual de las personas migrantes cuyo traslado es por tierra y que tienen menos recursos económicos.

Aún estas excepcionalidades están permeadas por un sesgo estatal que enfatiza la seguridad, control y selectividad sobre la población inmigrante, abriendo nuevamente un camino hacia potenciales situaciones discrecionales en Ecuador. En el documento oficial que proclama el proceso de regularización, se subraya que, en más de diez ocasiones, Ecuador extendió oficialmente la declaratoria de situación de emergencia con motivo de la magnitud de los flujos de venezolanos. Además, se acentúa que esta situación de emergencia "evidencia la necesidad de adoptar medidas para garantizar una migración ordenada y segura". ${ }^{93}$ La visa Verhu posee otro matiz si se atiende a que la Ley Orgánica de Movilidad Humana ecuatoriana asegura que la protección por razones humanitarias y la posibilidad de acceder a un visado humanitario está circunscripta a las personas extranjeras. "siempre y cuando no sean considerados una amenaza o riesgo para la seguridad interna según la información que dispone el Estado ecuatoriano". ${ }^{44}$ Las mismas condiciones se mencionan para poder obtener la residencia temporal en Ecuador. ${ }^{95}$

Para acceder al proceso de regularización excepcional a través de la visa Verhu, los migrantes venezolanos debían cumplir las siguientes condiciones: presentar un pasaporte vigente o que este tuviera máximo cinco años de vencido; antecedentes penales apostillados, legalizados o validados; en caso de tener hijos menores, se necesitaban las partidas de nacimiento apostilladas; $y$, si se trataba hipotéticamente de una visa gratuita, debían pagar el formulario de cincuenta dólares. Aunque existía la posibilidad de tener un descuento

\footnotetext{
${ }^{93}$ Decreto 826: Otórguese una amnistía migratoria para todas las ciudadanas y ciudadanos venezolanos que no hayan violado las leyes del Ecuador y que hayan ingresado regularmente a través de los puntos de control migratorio al territorio del Ecuador o se encuentren en condición migratoria irregular por haber excedido el tiempo de permanencia otorgado a la fecha de entrada en vigencia de este Decreto Ejecutivo, Quito, viernes 26 de julio, 2019, registro oficial, Año 1, núm. 5, p. 3.

${ }^{94}$ Ley Orgánica de Movilidad Humana, de 5 de enero de 2017, que regula el ejercicio de derechos, obligaciones, institucionalidad y mecanismos vinculados a las personas en movilidad humana, Quito, registro oficial (suplemento), 6 de febrero, 2017, núm. 938, art. 58.

${ }^{95}$ Ley Orgánica de Movilidad Humana, de 5 de enero de 2017, que regula el ejercicio de derechos, obligaciones, institucionalidad y mecanismos vinculados a las personas en movilidad humana, Quito, registro oficial (suplemento), 6 de febrero, 2017, núm. 938, art. 85.
} 
como pensionado o de gratuidad en caso de discapacidad, ese costo representó un impedimento para gran parte de las regularizaciones, debido a la precaria situación económica de esta población. Encima, esta se profundizó aún más con la crisis del coronavirus. Ello se deja entrever en los numerosos casos que, en vez de realizar un único pago bancario, lo hicieron en cuotas a medida que iban reuniendo los fondos. Tal situación provocó confusiones en los funcionarios y dificultó la conclusión de su proceso de regularización.

La primera fase del trámite de regularización era en línea, creando un usuario en la página web dispuesta para ello. Este fue uno de los principales escollos, dado que existían dos formularios electrónicos diferentes, según se hiciera la postulación, ya estando en el país o desde el extranjero. Otro problema fue que se requería una dirección de correo electrónico por persona y muchas familias remitían la misma.

Una vez adjuntados los documentos, realizado el pago bancario y recibida la confirmación por correo electrónico, los migrantes debían apersonarse para registrar sus datos biométricos, paso ineludible del Estado en estos momentos, cuando "controlar para proteger" encarna la idea de lo que se considera migración ordenada y segura.

Un cálculo parcial apunta a que, tan solo en los cuatro primeros meses estipulados para postular a la visa Verhu, Ecuador concedió 9001 de estos visados a venezolanos, representando con ello un exiguo porcentaje de los 2000 ingresos diarios que se contabilizaban antes de esta medida, en el principal paso fronterizo con Colombia. ${ }^{96}$

Con motivo del coronavirus, el Gobierno ecuatoriano suspendió las tramitaciones de esta visa humanitaria y extendió el plazo a sesenta días contados a partir de la finalización del estado de excepción en Ecuador. A pesar de ello, el accionar gubernamental contradijo el Decreto Ejecutivo 1020 que lo disponía. En la práctica, se decidió que el plazo para esta regularización extraordinaria terminaría el 13 de agosto, el mismo día que finalizaría el estado de excepción. Este cambio dejó en desventaja a las personas que necesitaban recaudar los costos del proceso, pero no podían trabajar debido a las restricciones de la pandemia y que, al quedar irregularizados, se convirtieron en migrantes pasibles de multas.

Con la letra del Decreto Ejecutivo 1020 y su aplicación, el Gobierno ecuatoriano dejó en entredicho el respeto a la norma y al principio de igualdad y

\footnotetext{
${ }^{96}$ Benalcázar, Washington, "La visa humanitaria desaceleró el ingreso de ciudadanos venezolanos", El Comercio, 31 de diciembre, 2019. Disponible en: https://www.elcomercio.com/actualidad/visa-humanitaria-ingreso-venezolanosecuador.html
} 
no discriminación utilizado para el colectivo venezolano, a cambio de reservar los derechos de la regularización solo para unos pocos.

\section{A modo de cierre:}

\section{¿Políticas migratorias de derechos humanos selectivas?}

Intentando romper con la idea binaria de que los derechos humanos son conquistas de las poblaciones subalternas o son imposiciones de las élites globales, en este artículo, partimos de que ambas concepciones subsisten en la campo jurídico nacional e internacional, sin que puedan sostenerse como contradictorias.

Se advierte, más bien, que los derechos humanos son polisémicos y actúan, como nuestras sociedades, bajo lógicas neoliberales por las cuales los derechos se vuelven moldeables a las necesidades políticas y de los mercados. Así, la vida de las personas migrantes obtiene reconocimiento jurídico o regularización, según el país de donde se provenga o la capacidad económica que se posea.

Por ello, nos preguntamos: ¿es posible construir una política de derechos humanos selectiva? Es decir, ¿una política que proteja derechos para unos y excluya a otros? Contar con una normativa que consagre el derecho humano a migrar debe condecirse con políticas de inclusión que eviten la discriminación por origen nacional. Si bien los Estados -dentro del juego de los derechos humanos - tienen la potestad de afianzar lazos con otros países para construir su política migratoria, estas diferencias tendrían que darse con criterios de razonabilidad y bajo los principios de igualdad y no discriminación.

Aunque Argentina y Ecuador han establecido el derecho a migrar como derecho humano, el acceso a este derecho se ha visto limitado o condicionado por decisiones gubernamentales traducidas en resoluciones, disposiciones, o normas de menor jerarquía que se contraponen a la Constitución y a las leyes nacionales, siguiendo el vaivén de los flujos migratorios y de los cambios políticos.

Las excepcionalidades que se mencionaron a lo largo del texto han propiciado el (re)fortalecimiento de medidas discriminatorias, de acuerdo con el origen nacional de las personas en movilidad, amparadas, muchas veces, en cuestiones que hacen a la seguridad del Estado y el control de las poblaciones. Esta creación de medidas de excepción, que no siempre cumplen con los principios de igualdad y no discriminación, contribuye a forjar un panorama desigual, donde, de acuerdo con el origen nacional y la capacidad de pago, se accede a ciertos beneficios o se encuentran mayores barreras. De este modo, se habilitan medidas discrecionales que, legitimas o no, al fin de cuentas, remiten a la exclusión. 
Nos interesa destacar las dificultades que subsisten en la implementación e interpretación de la ley. Para ello, detallamos los límites en el acceso a la radicación en Argentina, donde se excluye de manera específica a determinados grupos de migrantes y a ciertas nacionalidades, especialmente aquellas provenientes de Estados que no son parte del Mercosur y que recaen con mayor rigor en nacionalidades racializadas.

Por su parte, en Ecuador, persisten serias trabas impuestas escalonadamente por el Estado, específicamente, para el ingreso de migrantes provenientes de Haití, Cuba y Venezuela. Así es como se tensa el derecho a migrar en paridad de condiciones.

Como se observó, tanto en Argentina como en Ecuador, existen disímiles posibilidades de obtener reconocimiento jurídico (regularización), según el país de donde se provenga o la capacidad económica de la que se disponga para alcanzar ese derecho. En el día a día, la forma en que se desarrollan los trámites permite rastrear la discriminación y la exclusión.

Esta imposibilidad de regularizarse indefectiblemente excluye a las personas migrantes del mercado de trabajo, las deja expuestas a procesos de expulsión. Con ello, se les somete a serios quiebres en su proyecto de vida o incluso a salvarla en momento de graves violaciones de derechos humanos en sus países. Además, se les discrimina y confina a estar por fuera de los circuitos formales de educación y de salud, lo cual puede tener consecuencias irremediables en la vida de las personas migrantes y sus hijos.

La regularización se ha destacado como un argumento dual para el control poblacional y el acceso a derechos, establecidos de manera indisociable. Hemos afirmado que, al omitir los principios de igualdad y no discriminación, los Estados provocan una fragmentación de la figura del migrante como sujeto de derechos, debilitando con ello la idea misma de los derechos humanos. El trato diferenciado que dan Argentina y Ecuador a distintas nacionalidades cristaliza una construcción desigual de las personas migrantes que conviven en un mismo territorio. 


\section{Bibliografía}

Agamben, Giorgio, La comunidad que viene, Valencia, Pre-textos, 1996.

Autor/a; Gil Araujo, Sandra; Rosas, Carolina, "Control migratorio y producción de irregularidad. Normas, prácticas y discursos sobre la migración en la Argentina de Cambiemos”, Forum. Revista Departamento de Ciencia Politica, en prensa.

BenAlCÁzAR, Washington, "La visa humanitaria desaceleró el ingreso de ciudadanos venezolanos”, El Comercio, 31 de diciembre, 2019. Disponible en: https://www. elcomercio.com/actualidad/visa-humanitaria-ingreso-venezolanos-ecuador.html

Boaventura de Sousa, Santos y Sena Martins, Bruno, “Introducción”, en Santos, Boaventura de Sousa y Sena Martins, Bruno (eds.) El pluriverso de los derechos humanos. La diversidad de las luchas por la dignidad, Buenos Aires, Akal, 2019. Bourdieu, Pierre, La dominación masculina, Barcelona, Anagrama, 2000.

Bнавна, Номі, Nuevas minorias, nuevos derechos: Notas sobre cosmopolitismos vernáculos, Buenos Aires, Siglo XXI, 2013.

CANCILLERIA DE ECUADOR, "Ecuador requerirá carta de invitación para ingreso de ciudadanos cubanos”, Boletín de prensa, núm. 014, 15 de enero de 2013. Disponible en: https://www.cancilleria.gob.ec/ecuador-requerira-carta-de-invitacion-paraingreso-de-ciudadanos-cubanos/

CAnCILlería de Ecuador, “Tourist Visa Requirement for Cuban citizens", 2015. Disponible en: https://www.cancilleria.gob.ec/tourist-visa-requirement-for-cuban-citizens/

CENTRO DE Estudios Legales y Sociales, Informe anual sobre la situación de los derechos humanos en Argentina, Buenos Aires, Siglo XXI, 2007.

Ceriani Cernadas, Pablo, "Nueva Ley: un paso hacia una concepción distinta de la migración”, en Rubén Giustiniani (ed.), Migración: un derecho humano, Buenos Aires, Prometeo, 2004.

Cerrutti, Marcela, "Gender and Intra-Regional Migration in South America”, Human Development Research Paper, núm. 12. Disponible en: https://mpra.ub.uni-muenchen.de/19192/1/MPRA_paper_19192.pdf

COALICIÓN POR LAS MigRACIONES y El Refugio, Informe alternativo sobre el cumplimiento de la Convención de Naciones Unidas de los derechos de todos los trabajadores migratorios y sus familiares (стмF), Quito, Coalición por las Migraciones y el Refugio, 2017.

Comisión Interamericana de Derechos Humanos, "Derechos humanos de migrantes, refugiados, apátridas, víctimas de trata de personas y desplazados internos: Normas y estándares del Sistema Interamericano de Derechos Humanos”, 2015. Disponible en: https://www.oas.org/es/cidh/informes/pdfs/MovilidadHumana.pdf

Corte Interamericana de Derechos Humanos, Condición Jurídica y Derechos de los Migrantes Indocumentados, Opinión Consultiva OC-18/03 de 17 de septiembre de 2003.

COURTIS, CoRINA, "Hacia la derogación de la Ley Videla: la migración como tema de labor parlamentaria en la Argentina de la década de 1990”, en Alejandro Grimson 
y Elizabeth Jelin (comps.), Migraciones regionales hacia la Argentina. Diferencia, desigualdad y derechos, Buenos Aires, Prometeo, 2006.

Courtis, Corina y PAceccA, MARÍA InÉs, "Migración y derechos humanos: una aproximación crítica al 'nuevo paradigma' para el tratamiento de la cuestión migratoria en la Argentina”, Revista Jurídica de Buenos Aires, núm. especial sobre derechos humanos.

Declaración Universal de Derechos Humanos, París, 10 de diciembre de 1948.

DOMENECH, EduARdo, “Crónica de una 'amenaza' anunciada. Inmigración e 'ilegalidad': visiones de Estado en la Argentina contemporánea”, en Bela Feldman-Bianco; Liliana, Rivera Sánchez; Carolina, Stefoni y Marta Inés Villa Martínez (comps.), La Construcción del sujeto migrante en América Latina: Prácticas, representaciones y categorías, Quito, Flacso-Clacso-Universidad Alberto Hurtado, 2011.

Domenech, EduARdo, "La ciudadanización de la política migratoria en la región sudamericana: vicisitudes de la agenda global”, en Susana Novick (comp.), Las migraciones en América Latina. Politicas, culturas y estrategias, Buenos Aires, Catálogos-Clacso, 2008.

Domenech, EduARdo, “'Las migraciones son como el agua': Hacia la instauración de políticas de 'control con rostro humano'. La gobernabilidad migratoria en la Argentina”, Polis. Revista Latinoamericana, vol. 12, núm. 35.

"Entre leyes y experiencias. El acceso a la justicia de las trabajadoras domésticas migrantes a comienzos del siglo XXI en la Ciudad Autónoma de Buenos Aires”, tesis de doctorado en Ciencias Sociales, Facultad de Ciencias Sociales, Universidad de Buenos Aires, 2017.

FASSIN, DidIER, La razón humanitaria. Una historia moral del tiempo presente, Buenos Aires, Prometeo, 2016.

FEDERICI, SilviA, La revolución feminista inacabada. Mujeres, reproducción social y lucha por lo común, México, Escuela Calpulli, 2013.

Ferrajoli, Luigi, "Políticas contra los migrantes y crisis de la civilidad jurídica”, Revista Crítica Penal y Poder, núm. 18.

Foucault, Michel, Vigilar y castigar: nacimiento de la prisión, Buenos Aires, Siglo XXI, 2003.

GARCÍA, LILA, "Migraciones, Estado y una política del derecho humano a migrar: ¿hacia una nueva era en América Latina?”, Colombia Internacional, núm. 88.

Góngora-Mera, Manuel; Herrera, Gioconda y Muller, Conrad, “The Frontiers of Universal Citizenship. Transnational Social Spaces and the Legal Status of Migrants in Ecuador”, Desigualdades, núm. 71, Berlin, Desigualdades International Research Network on Interdependent Inequalities in Latin America, 2014.

Grosfoguel, RAmón, El giro decolonial, reflexiones para una diversidad epistémica más allá del capitalismo global, Bogotá, Encuentros, 2007.

Herrera, Gioconda y Cabezas Gálvez, Gabriela, "Ecuador: de la recepción a la disuasión. Políticas frente a la población venezolana y experiencia migratoria 2015-2018”, 
en Luciana Gandini, Fernando Lozano Ascencio y Victoria Prieto (coords.), Crisis y migración de la población venezolana. Entre la desprotección y la seguridad jurídica en Latinoamérica, México, UNAM, 2019.

HinÉs, BÁRBARA, "El derecho a migrar como un derecho humano: La actual ley inmigratoria argentina”, Revista Derecho Público (Argentina), año 1, núm. 2.

Ley 25.871, Buenos Aires, 17 de diciembre de 2003, Boletín Oficial, 21 de enero de 2004.

Maguid, Alicia, "La migración internacional reciente en la Argentina. Características e impacto en el mercado de trabajo”, en Manuel Ángel Castillo, Alfredo Lattes y Jorge Santibáñez (coords.), Migración y fronteras, México, Colef-Somede-Colmex, 1998.

MigRAción y Asilo iJDHun, "Diálogo con la Directora Nacional de Migraciones, Florencia Carignano, coordinado por Pablo Ceriani Cernadas, director de la Especialización en Migración y Asilo, Instituto de Justicia y Derechos Humanos (IJDH), Universidad Nacional de Lanús, Buenos Aires”, 18 de junio, 2020. Recuperado de: facebook. com/migracionIJDHUNLa

Ministerio de Relaciones Exteriores y Movilidad Humana, Acuerdo Ministerial núm. 242, Quito, 16 de agosto, 2018.

Modolo, VAnina, “Movilidad territorial en el Mercado Común del Sur. La construcción del residente mercosureño y el Estado argentino (1991-2012)”, tesis de doctorado en Ciencias Sociales, Facultad de Ciencias Sociales, Universidad de Buenos Aires, 2013.

Neiman, Guillermo y Quaranta, Germán, "Los estudios de caso en la investigación sociológica”, en Gialdino Vasilachis (comp.), Estrategias de investigación cualitativa, Buenos Aires, Gedisa, 2006.

Nikken, Pedro, "El concepto de derechos humanos", en Estudios básicos de derechos humanos, San José, IDHH, 1994.

Novick, Susana, Cómo trabajar con textos jurídicos en ciencias sociales, documento de trabajo núm. 69, Buenos Aires, Instituto de Investigaciones Gino Germani, Facultad de Ciencias Sociales, Universidad de Buenos Aires, 2014.

Novick, Susana, "Migración y políticas en Argentina: Tres leyes para un país extenso (1876-2004)", en Susana Novick (comp.), Las migraciones en América Latina: politicas, culturas y estrategias, Buenos Aires, Catálogos-Clacso, 2008.

Organización InTERnACIONAL PARA LAS Migraciones, "La migración dominicana en Argentina. Trayectorias en el nuevo siglo (2000-2015)”, Buenos Aires, oIm-Caref, 2015 Organización Internacional para las Migraciones, Portal de Datos Mundiales sobre la Migración. Disponible en: https://migrationdataportal.org/es?i=stock abs_Ctt=2019\&tcm49=218

Organización Internacional para las Migraciones y Consejo Nacional de Coordinación De Políticas Sociales, "Escenario base para el seguimiento de los objetivos de desarrollo sostenible vinculados a las condiciones de vida de los migrantes a 
través del gasto público social nacional”, 2018. Disponible en: http://argentina. iom.int/co/sites/default/files/publicaciones/Escenario\%20base\%200DS\%20 Condiciones\%20de\%20Vida\%20Migrantes\%20\%20WEB\%20FINAL.pdf

Ortiz Pinos, Dolores, "La inmigración de jóvenes haitianos a la ciudad de Cuenca y sus proyectos de vida en el marco de las políticas migratorias ecuatorianas" tesis de maestría en Migración, Derechos Humanos y Políticas Públicas, Facultad de Ciencias Económicas y Administrativas, Universidad de Cuenca, 2016.

PACECCA, MARía InÉs, "El Mercosur y la normativa migratoria argentina (2000-2005)”, en VII Congreso Nacional de Ciencia Política de la Sociedad Argentina de Análisis Político, Buenos Aires, 15-18 de noviembre de 2006.

Pacecca, María InÉs, "Personas, papeles, políticas y derechos: las migraciones contemporáneas en Argentina desde la perspectiva de Caref, 2004-2015”, en María Inés Pacecca, Ciudad Autónoma de Buenos Aires, Caref Comisión Argentina para Refugiados y Migrantes, 2019.

Pacecca, María Inés; Canelo, Brenda y Belcic, Sofía, “Culpar a los negros y a los pobres. Los 'manteros' senegaleses ante los allanamientos en el barrio de Once”, en María Victoria Pita y María Inés Pacecca (eds.), Territorios de control policial. Gestión de ilegalismos en la Ciudad de Buenos Aires, Buenos Aires, Editorial Facultad de Filosofía y Letras de la Universidad de Buenos Aires, 2017.

Pacecca, María InÉs y ChaivetTA, VALERIA, El DNI ¿más lejos o más cerca? Regularización y documentación de migrantes a través del sistema Radex, Buenos Aires, Observatorio sobre Migraciones y Asilo en Argentina "Gabriel Chausovsky”, 2020. Disponible en: https://drive.google.com/file/d/139zi0E1zVfoIa8lwhZNA8Mu_AgiGRRoU/view Pérez Rabasa, Jeremías y Jaramillo Fonnegra, Verónica, “La criminalización de la migración y el rol de las transnacionales en los países de destino: el caso de senegaleses en Barcelona y Buenos Aires”, Revista De Estudios E Pesquisas Sobre As Américas, vol. 13, núm. 1.

Presidencia de la RePÚBlica del EcuAdor, "Proyecto de ley orgánica reformatoria a la ley orgánica de movilidad humana”, Quito, Oficio T.068-SGJ-19-0574, 29 de julio de 2019.

Quiloango Tipanluisa, Susana, "Políticas públicas migratorias en el Ecuador", Documentos de Trabajo, Quito, Fundación Friedrich Ebert, 2011.

$\mathrm{R} 4 \mathrm{~V}$, "Plataforma de coordinación para refugiados y migrantes de Venezuela". 101

Disponible en: https://r4v.info/es/situations/platform

RAJAgOPAL, BALAKRISHNAN, "Los límites del derecho en la globalización contrahegemónica: la Corte Suprema de la India y la lucha en el valle de Narmada”, en Santos, Boaventura de Sousa y Rodríguez Garavito, César (eds.), El derecho y la globalización desde abajo: Hacia una legalidad cosmopolita, Barcelona-México, Anthropos-UAM, 2007, pp. 167-196.

Ramírez, Jacques; Ceja, Iréri; Coloma, Soledad y Arteaga, Romina, “'Ha, usted viene por la visa Mercosur’: Migración, integración y refugio en Ecuador”, Quito, Celag, 2017. 
Ramírez, Jacques; LinÁrez, Yoharlis y Useche, Emilio, “(Geo)políticas migratorias, inserción laboral y xenofobia: migrantes venezolanos en Ecuador”, en Cécile Blouin (ed.), Después de la llegada. Realidades de la migración venezolana, Lima, ThemisPUCP, 2019.

Robles, Diego, "El acceso a la justicia: aspectos teóricos, implicancias prácticas", en Manuela González y Carlos Lista (coords.), Sociología jurídica en Argentina: tendencias y perspectivas, Buenos Aires, Eudeba, 2011

SASSEN, SASKIA, Contrageografías de la globalización. Género y ciudadanía en los circuitos transfronterizos, Madrid, Traficantes de Sueños, 2003.

Spivak, Gayatri Chakravorty, A Critique of Postcolonial Reason: Toward a History of the Vanishing Present, Cambridge, Harvard University Press, 1999.

Universidad Nacional de Lanús, “¿Regresividad en Derechos Humanos? El Decreto de Necesidad y Urgencia 70/17 y su impacto en el acceso a la justicia de las personas migrantes frente a los procedimientos de expulsión y detención”, pedido de informes realizado en el marco del Proyecto Oscar Varsavsik, 2018.

Universidad Nacional de Lanús y Comisión para Refugiados y Migrantes de la Argentina, "Pedido de informes a la Dirección Nacional de Migraciones", 2019.

YIN, RoBert, Case study research: Design and methods, California, Sage, 1994. 